\title{
Mouse $V_{k}$ gene classification by nucleic acid sequence similarity
}

\author{
Robert Strohal, Arno Helmberg, Guido Kroemer, and Reinhard Kofler \\ Institute for General and Experimental Pathology, University of Innsbruck Medical School, Innsbruck, Austria
}

\begin{abstract}
Analyses of immunoglobulin $(I g)$ variable $(V)$ region gene usage in the immune response, estimates of $V$ gene germline complexity, and other nucleic acid hybridization-based studies depend on the extent to which such genes are related (i. e., sequence similarity) and their organization in gene families. While mouse Igh heavy chain $V$ region $\left(V_{H}\right)$ gene families are relatively wellestablished, a corresponding systematic classification of $I g k$ light chain $V$ region $\left(V_{k}\right)$ genes has not been reported. The present analysis, in the course of which we reviewed the known extent of the $V_{k}$ germline gene repertoire and $V_{k}$ gene usage in a variety of responses to foreign and self antigens, provides a classification of mouse $V_{k}$ genes in gene families composed of members with $>80 \%$ overall nucleic acid sequence similarity. This classification differed in several aspects from that of $V_{H}$ genes: only some $V_{k}$ gene families were as clearly separated (by $>25 \%$ sequence dissimilarity) as typical $V_{H}$ gene families; most $V_{k}$ gene families were closely related and, in several instances, members from different families were very similar ( $>80 \%)$ over large sequence portions; frequently, classification by nucleic acid sequence similarity diverged from existing classifications based on amino-terminal protein sequence similarity. Our data have implications for $V_{k}$ gene analyses by nucleic acid hybridization and describe potentially important differences in sequence organization between $V_{H}$ and $V_{k}$ genes.
\end{abstract}

\section{Introduction}

The ability of the immune system to recognize virtually any antigen is mediated by the enormous sequence variability in the amino-terminal region of immunoglobulin (Ig) heavy and light chains. Among other

Address correspondence and offprint requests to: Dr. Reinhard Kofler, Institute for General and Experimental Pathology, Fritz-Pregl-Straße 3, A-6020 Innsbruck, Austria. mechanisms, this diversity is generated by somatic juxtaposition of gene segments that are separated in the germline, termed variable $(V)$, diversity (heavy chain only), and joining $(J)$ gene segments (reviewed by Tonegawa 1983, Alt et al. 1986). $V$ genes contribute all residues of the first and second complementarity determining region (CDR) of both heavy and light chains, as well as part of the light chain CDR-3, and hence contribute the majority of antigen contact residues (Kabat et al. 1987). In mice, several hundred $V_{H}$ and $V_{k}$ (over $90 \%$ of all serum Ig is of the Igk isotype) gene segments exist in the germ line (Brodeur and Riblet 1984, Livant et al. 1986, Cory et al. 1981, Kofler et al. 1989). These genes can be very similar or may differ by over $40 \%$ nucleotides, and $V$ region classifications based on nucleic and/or amino acid sequence similarity have been proposed (Brodeur and Riblet 1984, Dildrop 1984, Potter et al. 1982). Thus, mouse $V_{H}$ genes have been grouped in $11 V_{H}$ gene families in which members generally share $>80 \%$ of their nucleic acid sequence within, and $<70-75 \%$ between, families (Brodeur and Riblet 1984, Winter et al. 1985, Kofler 1988, Reininger et al. 1988). Individual members of a given family cross-hybridize in nucleic acid hybridization assays only with members of their own family. These $V_{H}$ gene families correspond well with a $V_{H}$ region classification based on similarities at the protein level (Dildrop 1984). Understanding $V_{H}$ gene relatedness on the nucleic acid sequence level has greatly facilitated studies regarding the expression of different $V_{H}$ gene families during ontogeny (Yancopoulos et al. 1984, Perlmutter et al. 1985 ) and in response to foreign and self antigens (Manser et al. 1987b, Kofler et al. 1987a). These studies have thus provided an important insight into B-cell repertoire generation.

$V_{k}$ classifications reported to date are confined to the protein level. One attempt to systematically classify $V_{k}$ proteins was based on the partial amino acid sequence up to the invariant cysteine in position 23 (Cys23), leading to $26 \mathrm{~V}_{\mathrm{k}}$ subgroups, designated $\mathrm{V}_{\mathrm{k}} \mathrm{Cys}$ (Potter 1977). A 
modified classification, based on the length and similarity of the amino termini up to the invariant tryptophan 35 (Trp35) of $79 V_{k}$ proteins, was introduced in 1982 $\left(V_{k} T r p\right.$ subgroups; Potter et al. 1982). Four of the $V_{k} C y s$ subgroups were condensed and two new groups were added, resulting in a total of $24 V_{k}$ subgroups, six of which are still defined only by sequences up to Cys23. This classification has now been generally accepted and, although an extended comparison at the nucleic acid level has never been reported, the corresponding $V_{k}$ protein subgroups have been widely used synonymously with $V_{k}$ gene families. More recently, we have performed a detailed restriction fragment length polymorphism (RFLP) analysis with DNA probes corresponding to $16 \mathrm{~V}_{\mathrm{k}}$ protein subgroups, and obtained evidence that such protein groups may not necessarily correspond to gene families analogous to those described for $V_{H}$ genes (Kofler et al. 1989). Since a large number of full-length $V_{k}$ nucleic acid sequences has been reported, it is now possible to address, by direct sequence comparison, the matter of whether $V_{k}$ genes can be organized into gene families, as has been accomplished with $V_{H}$ genes, and how such $V_{k}$ gene families relate to the existing $V_{\mathrm{k}}$ protein groups. This issue is of considerable interest for $V_{k}$ gene usage determinations, repertoire estimates, genomic mapping, and similar studies using nucleic acid hybridization, since such procedures depend on relatedness between $V_{k}$ groups, gene families, and corresponding DNA probes.

We compiled 248 full-length $V_{k}$ nucleic acid sequences from the literature and several databases, and assigned them to existing $V_{k}$ protein classifications with subsequent grouping into gene families comprised of members with $>80 \%$ overall nucleic acid sequence similarity. Our analysis revealed that the current classification in $V_{k}$ protein groups or subgroups frequently did not reflect relatedness on the nucleic acid sequence level. Furthermore, $V_{k}$ gene family organization differed in important aspects from that of $V_{H}$ gene families; only some of the $V_{k}$ gene families were clearly separated by sequence dissimilarity of $>25 \%$, as is usually observed in $V_{H}$ gene families. The remaining families were more similar to each other and, in several instances, large portions of genes from different families shared $>80 \%$ of their sequences, leading to cross-hybridization between those families in hybridization analyses. In addition, although ancillary to the primary aim of this study, we reviewed the specificities encoded by the various $V_{k}$ gene families and estimated their germline gene complexity.

\section{Methods and nomenclature}

$V_{k}$ nucleic acid sequence bank. A database was constructed consisting of $V_{k}$ nucleic acid sequences from the Genetic Sequence Data Bank (GenBank, Los Alamos, New Mexico), E. A. Kabat's collection (Kabat et al. 1987), and other publications. Only sequences encoding the entire mature $V_{k}$ protein were included in the database. If applicable, sequence portions encoding untranslated region, leader sequence, introns, or $J$ segments were removed prior to comparisons. This primary database of 248 full-length $V_{k}$ sequences was then condensed to a final database of 109 (Fig. 1) by deleting duplicate sequences and those differing by only 1 to 4 base pairs (bp).

$V_{k}$ protein groups and subgroups. All nucleic acid sequences were translated into amino acids and organized into $V_{k}$ protein groups and subgroups. Assignment to $V_{k}$ protein groups (labeled I to VII) was based on the length of the amino-terminal sequence up to the invariant $\operatorname{Trp} 35$ $(41,40,39,36,35,34$, and 33 residues, respectively; Kabat et al. 1987). Organization into $V_{k}$ protein subgroups was based on $<13$ substitutions up to Trp35 ( $V_{k} T r p$ subgroups; Potter et al. 1982). Sequences meeting assignment criteria for more than one subgroup were assigned to the subgroup with the best match.

$V_{k}$ gene families. Analogous to $V_{H}$ gene families, we defined a " $V_{k}$ gene family" as a group of nucleic acid sequences that exhibit $>80 \%$ overall sequence similarity with every member of this family, and $<80 \%$ with $V_{k}$ genes from other families. In nucleic acid hybridization analyses under defined stringency conditions (Brodeur and Riblet 1984), all members of a gene family can be expected to cross-hybridize with each other. The $V_{k}$ gene family nomenclature proposed in this study was adjusted as far as possible to that used for $V_{k}$ protein subgroups, in order to minimize confusion in the literature; when $V_{k}$ protein subgroups and $V_{k}$ gene familes corresponded to each other (e.g., $V_{k} 21$ ), the $V_{k}$ subgroup designation was used for the $V_{k}$ gene family as well. $V_{k}$ gene families comprising two or more $V_{k}$ protein subgroups were given the designation of the respective subgroups (e.g., the $V_{k} 4 / 5$ gene family comprised $V_{k} 4$ and $V_{k} 5$ protein subgroups). Addition of capital letters to the designation indicates that $a V_{k}$ protein subgroup included members from two distinct $V_{k}$ gene families (e.g., the $V_{k} 9$ protein subgroup comprised members from two distinct $V_{k}$ gene families, termed $V_{k} 9 A$ and $V_{k} 9 B$, respectively). $V_{k} R F$ and (tentatively) $V_{k} 38 C$ were two new gene families that could not be related unambiguously to any $V_{k}$ protein subgroup and, hence, were named after a prototypic sequence.

\section{Organization of mouse $V_{k}$ sequences on the protein and nucleic acid level}

The major goal of this study was to investigate the organization of mouse $V_{k}$ genes in terms of nucleic acid sequence similarity, and to determine the relationship of such organization to existing $\mathrm{V}_{\mathrm{k}}$ protein classifications. To this end, we first compiled 109 distinct (i. e., $>4$ bp different), full-length $V_{k}$ nucleic acid sequences that were used as a database for subsequent analyses (Fig. 1). The sequences were translated into amino acids (Fig. 2) and assigned to protein groups and subgroups (Table 1).

Classification into protein groups was based on the number of residues up to the invariant $\operatorname{Trp} 35$ and, hence, was unambiguous in all instances. However, this classification was of limited practical value, since it frequently did not reflect structural relatedness (i. e., sequence similarity) between $V_{k}$ sequences. For example, group $\mathrm{V}$ included members of several, sometimes quite dissimilar, $V_{k}$ gene families $\left(V_{k} 23, V_{k} 12 / 13, V_{k} R F, V_{k} 11\right.$, $\left.V_{k} 9 A, V_{k} 9 B, V_{k} 10, V_{k} 38 C, V_{k} 19 / 28\right)$. On the other hand, 
A 001

\section{$10+20$} 20

30

FR1 40 MACATTGTGCTGACCCAATCTCCAGCTTCTTTGGCTGTGTCTCTAGGGCAGAGGGCCACCATATCCTGC AGAGCCAGTGAAAGTGTTATAGT . .... TAT GACATTGTGCTGACCCAATCTCCAGCTTCTTTGGCTGTGTCTCTAGGGCAGAGGGCCACCATATCCTGC AGAGCCAGTGAAAGTGTTGATAGT...... TAT GACATTGTGCTGACACAGTCTCCTGCTTCCTTAGCTGTATCTCTGGGGCAGAGGGCCACCATCTCATGC AGGGCCAGCAAAAGTGTCAGTACA..... TCT GACATTGTGCTAACACAGTCTCCTGCTTCCTTAGCTGTATCTCTGGGGCAGAGgGCCACCATCTCATGC AGgGCCAGCCAAAGTGTCAGTACA...... TCT GACATTGTGCTGACCCAATCTCCAGCTTCTTTGGCTGTGTCTCTAGGACAGAGAGCCACTATCTTCTGC AGAGCCAGCCAGAGTGTCGATTAT...... AaT GACATTGTGCTGACCCAATCTCCAGGATCTTTGGCTGTGTCTCTAGGGCAGAGGGCCACCATATCCTGC AGAGCCAGTGAAAGTGTTGAAAGT..... TCT AAAATTGTGCTGACCCAATTTCCAGCTTCTTTGGCTGTGTCTCTAAGGCAGAGGGCСACCATATCCTGC AGAGCCAGTGAAAGTGTTGATAGT..... TAT GACATTGTGCTCACCCAATCTCCAGCTTCTTTGGCTGTGTCTCTAGGGCAGAGTGTCACCATCTCCTGC AGAGCCAGTGAAAGTGTTGAATAT..... TAT GACATTGTGCTGACACAGTTTCCTGCTTCCTTAGCTGTATCTCTGGGGCAGAGGGCCACCATCTCATAC AGGGCCAGCAAAAGTGTCAGTACA..... TCT

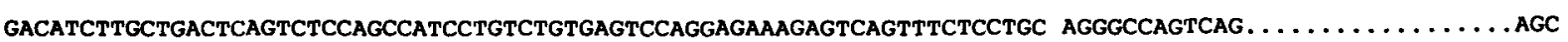

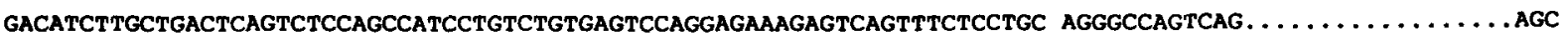
GACATCTTGCTGACTCAGTCTCCAGCCATCCTGTCTGTGAGTCCAGGAGAAAGAGTCAGTTTCTCCTGC AGGGCCAGTCAG................

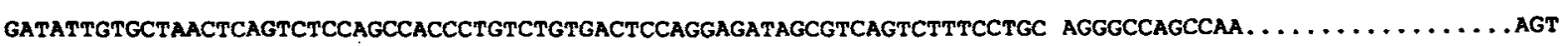

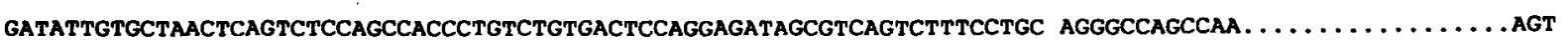

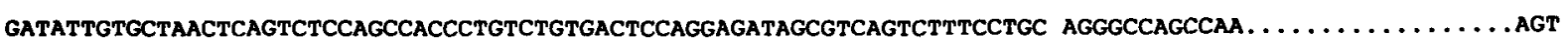

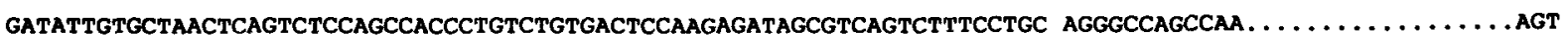
CAAATTGTTCTCACCCAGTCTCCAGCAATCATGTCTGCATCTCCTGGGGGAAGGTCACCATGACCTGC AGTGCCAGATCAAGT............ GAAAATGTGCTGACCCAGTCTCCAGCAATCATGGCTGCATCTCCAGGGGAGAAGGTCACCATGACCTGC AGTGCCAGCTCAAGT.............

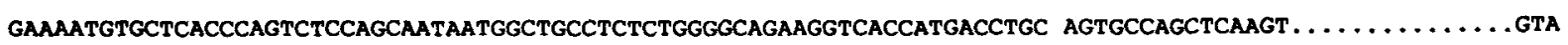

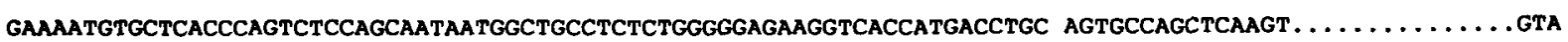
CAAATTGTTCTCACCCAGTCTCCAGCAATCATGTCTGCCTCTCCAGGGGAGAaGGTCACCATGACCTGC AGTGCCAGCTCAAGT........... GTA

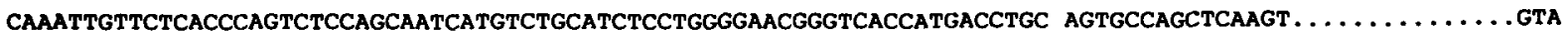

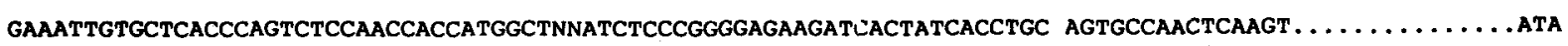

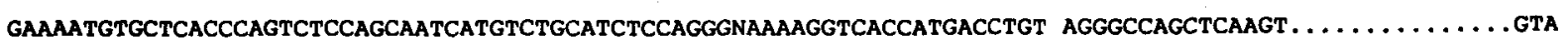

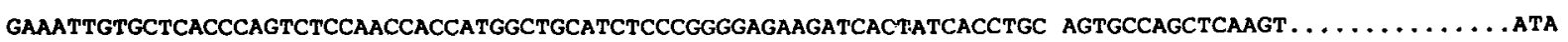

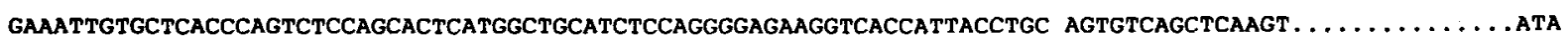

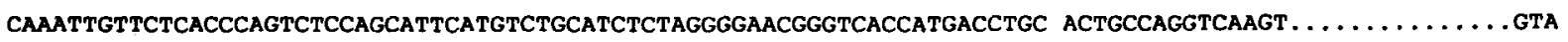

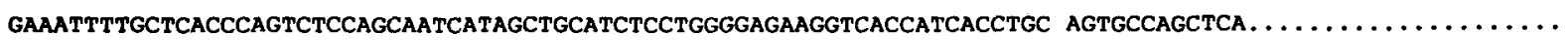

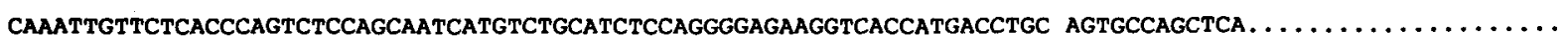

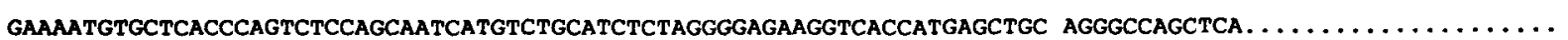

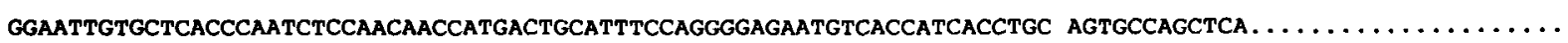

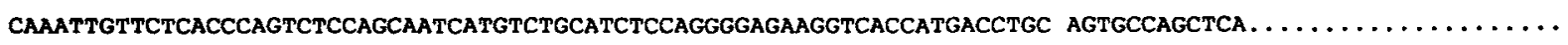

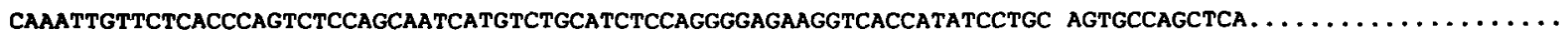

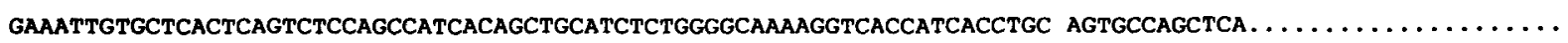

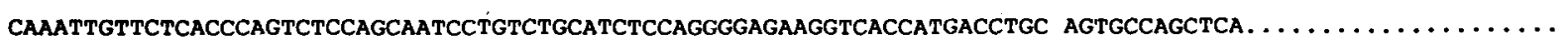

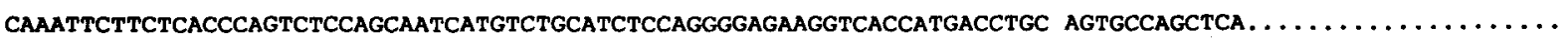

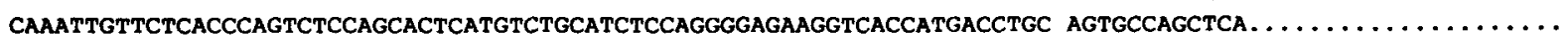

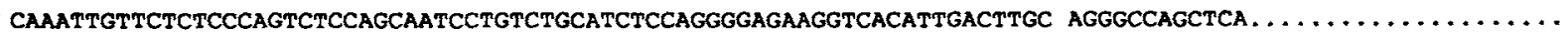

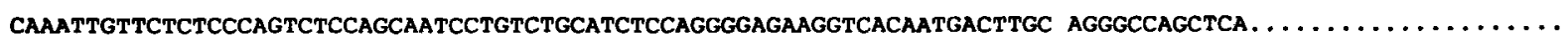

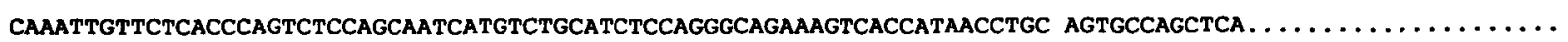

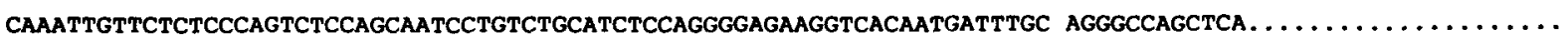

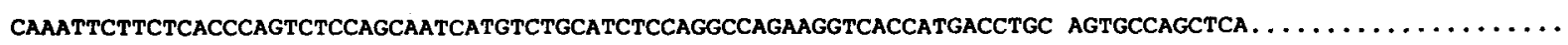

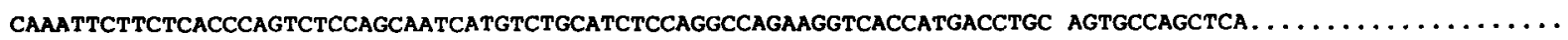

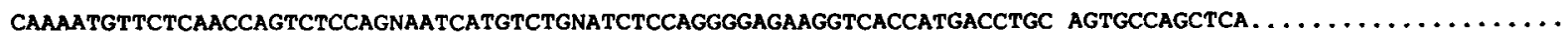

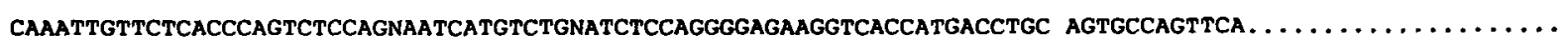

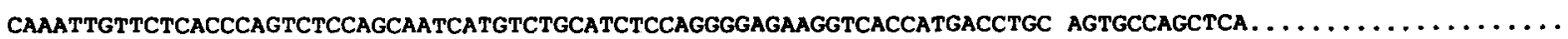

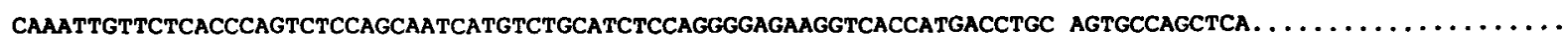

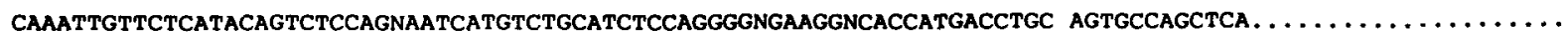

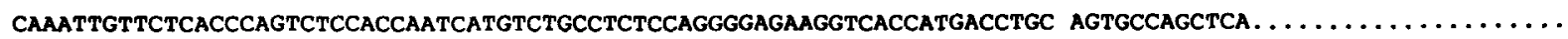

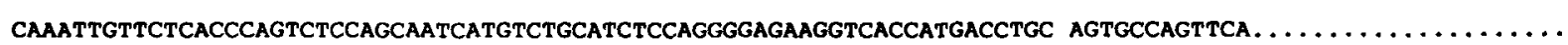

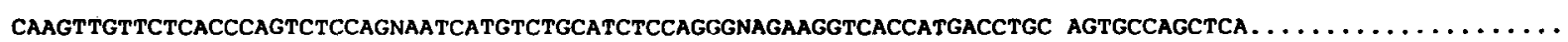

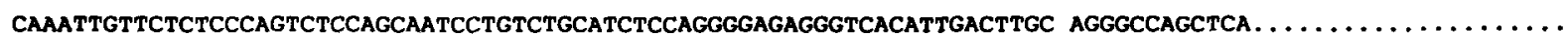

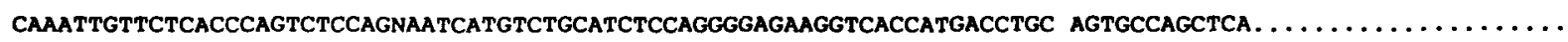

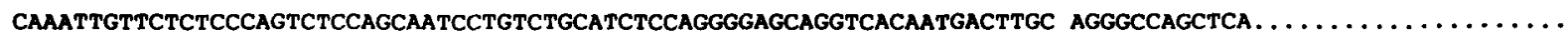


8

001

002

003

004

005

006

007

008

009

010

011

012

013

014

015

016

017

018

$0: 9$

020

021

CDRI

110

$120^{\circ}$ $2 0 \longdiv { 1 3 0 }$ 140 F $22-150$ 160 170 CDR2 180 $\sqrt{190} \mathrm{FA3}-200$

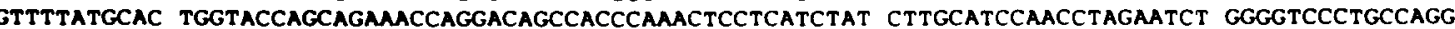
GGCAATAGTTTTATGCAC TGgTACCAGCAGAAACAGGACAGCCACCCAAACTCCTCATCTAT CGTGCATCCAACCTAGAATCT GGGATCCCTGCCAGG GCCTATAGTTATATGCAC TGGTACCAACAgAACCAGgACAGCCACCCAAACTCCTCATCTAT CTTGCATCCAACCTAGAATCT GGGGTCCCTGCCAGG

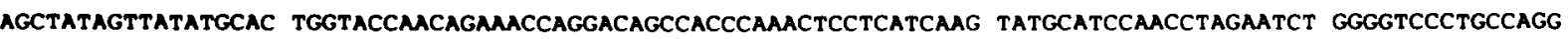
GGAATTAGTTATATGCAC TGGTTCCAACAGAAACCAGGACAGCCACCCAAACTCCTCATCTAT GCTGCATCCAACCTAGAATCT GGGATCCCTGCCAGG GGCAATAATTTATCCAC TGGCACCAGCAGAAACCAGGACAGCCACCCNAACTCCTCATCTAT CGTGCATCCAACCTAGCATCT GGGATCCCTGCCAGG GGCAATAGTTTTATGTAC TGGTACCAGCAGAAACAgGACAGCCACCCAAACTCCTCATCTAT CGTGCATCCAACCTAGAATCT GGGGTCCCTGCCAGG

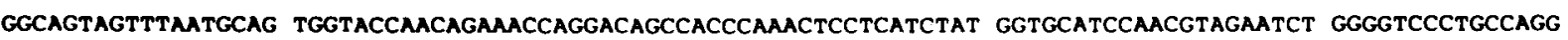
GGCTATAGTTATATGCAC TGGAACCAACAGAAACCAGGACAGCCACCCAGACTCCTCATCTAT CTTGTATCCAACCTAGAATCT GGGGTCCCTGCCAGG ATTGGCACAAGCATACAC TGgTATCAgCAAAGAACAAATGgTTCTCCAAGgCtTCTCATAAAg TATGCTTCTGAGTCTATCTCT GGGATCCCTTCCAGG ATTGGCACAAGCATACAC TGGTATCAGCAAAGAACAAATGGTTCTCCAAGGCTTCTCATAAAG AATGCTTCTGAGTCCATCTCT GGGATCCCTTCCAGG ATTGGCACMAGTCTTCAC TGGTATCAACAAAGAACAAATGGTTCTCCAAGGCTTCTCATAAAg TATGCTTCTGAGTCTATCTCT GGGATCCCTTCCAGG ATTATCAACMCCTACAC TTATATCGATAAAAATCACATGAGTCTCCAAGGCTTCTCATCAAA TATGCTTCCCAGTCCATCTCT GGGATCCCCTCTAGG ATTAGCAACAMCCTACAC TGGTATCAACAAAAATCACATGAGTCTCCAAGGCTTCTCATCAAT TATGCCTCCCAGTCCATGTCT GGGATCCCCTCCAGG ATTAGCAACAACCTACAC TGGTATCAACAAAAATCACATGAGTCTCCAAGGCTTCTCATCAAG TATGCTTCCCAGTCCATCTCT GGGATCCCCTCCAGG ATTAGCAACAACCTACAC TGgTATCAACAAAAATCACATGAGTCTCCAAGGCTTCTCATCAAA TATGCTTCCCAGTCCATCTCT GGGATCCCCTCTAGG AGTTCCAGCTACTTGTAC TGGTACCAGCAGAAGCCAGGATCCTCCCCCAAACTCTGGATTTAT AGCACATCCAACCTGGCTTCT GGAGTCCCTGCTCGC AGTTCTAGTAACTTGCAC TGGTACCAGCAGAAGTCAGGCACTTCTACCAAATTCTGGATTTAT AGGACATCCAACCTGGCTTCA GAAGTCCCAGCTCCC AGTTCCAGTTACTTGCAC TGGTACCAGCAGAAGTCAGGCGCTTCCCCCAAACCCTTGATTCAT AGGACATCCAACCTGGCTTCT GGAGTCCCAGCTCGC AGTTCCAGCTACTTGCAC TGGTACCAGCAGAAGTCAGGCACTTCCCCCAAACTCTGGATTTAT GGCACATCCAACCTGGCTTCT GGAGTCCCAGCTCGC AGTTCCAAATACTTGAAC TGGTACCAGCAGAGGTCAGGAGCCTCCCCCAAACTCTGGATTTAT GGCACATCCAACCTGGCTTCT GGAGTCCCTGCTCGC AGTTCCAGCTACTTGTAC TGGTACCAGCAGAAGCCAGGATCCTCCCCCAAACTATGGATTTAT AGCACATCCAACCTGGCTTCT GGAGTCCCTGCTCGC AGTTCCAATTACTTGCAT TGGTATCAGCAGAAGCCAGGATTCTCCCCTAAACTCTTGATTTAT AGGACATCCAATCTAGCTTCT GGAGTCCAAGCTCGC AGTTCCAGTTACTTGCAC TGGTACCAGCAGAAGTCAGGTGCCTCCCCCAAACTCTGGATTTAT AGCACATCCAACCTGGCTTCT GGNGTCCCTGCTCGC AGTTCCAATTACTTGAAT TGGTTTCAGCAGAAGCCAGGATTCTCCCCTAAACTCTTGATTTAT AGGACATCCAATCTGGCTTCT GGAGTCCCAGATCGC AGTTCCAGCAACTTGCAC TGGTACCAGCAGAAGTCAGAAACCTCCCCCAAATCTTGGATTTAT GGCACATCCAACCTGGCTTCT GGAGTCCCTGTTCGC AGTTCCAGTTACTTCCAC TGGTACCAGCAGAAGCCAGGATCCTCCCCCAAACTCTGGATTTAT AGCACATCCAACCTGGCTTCT GGAGTCCCAACTCGC AGTGTAAGTTACATGAAC TGGTACCAGCAGAAACCAGgATCCTCCCCCAAAATATGGATTTAT GgTATATCCAACCTGGCTTCT GGAGTTCCTGCTCGC AGTATAAGTTACATGCAC TGGTACCAGCAGAAGCCAGGCACCTCCCCCAAAAGATGGATTTAT GACACATCCAAACTGGCTTCT GGAGTCCCTGCTCGC AgTGTAAATTACATGTAC TGGTACCAGCAGAAGTCAGATGCCTCCCCCAAACTATGGATTTAT TACACATCCAACCTGGCTCCT GGAGTCCCAGCTCGC AGTATAAATTACATTCAC TGGTACCAGCAGAAGTCAGGAAATACCCCCAAACAATGAATTTAT AAGACATCCGACCTGCCTTCT GGAGTCCCAACTCTC AGTGTAAGTTACATGCAC TGgTACCAGCAGAagtCAGgCACCTCCCCCAAAAGATGGATTTAT GACACATCCAAACTGGCTTCT GGAGTCCCTGCTCGC AGTGTAAGTTACATGTAC TGGTACCAGCAGAAGCCAGGATCCTCCCCCAAACCCTGGATTTAT CGCACATCCAACCTGGCTTCT GGAGTCCCTGCTCGC

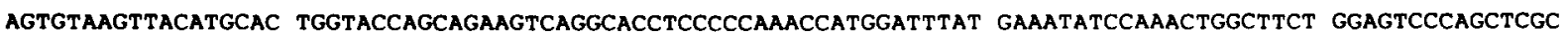
AGTGTAAGTTACATGTAA TGGTTCCAGCAGAAGCCAGGATCCTCCCCCAAACTCTGGATTTAT AGCATATCCAACCTGGCTTCT GGAGTCCCTGCTCGC AGTGTAAGTTACATGCAC TGGTACCAGCAGAaGCCAGGATCCTCGCCCAAACCCTGGATTTAT GACACATCCAACCTGGCTTLT GGATTCCCTGCTCGC AGTGTAAGTTACATGTAC TGGTACCAGCAGAAGCCAAGATCCTCCCCCAAACCCTGGATTTAT CTCACATCCAACCTGGCTTCT GGAGTCCCTGCTCGC AGTGTAAGTTTCATGAAC TGGTACCAGCAGAAGCCAGGATCCTCCCCCAAACCCTGGATTTAT GCCACATCCAATTTGGCTTCT GAGTTCCCTGGTCGC AGTGTAAGTTACATGCAC TGGTACCAGCAGAAGCTTGGATCCTCCCCCAAACCATGGATTTAT GCCACATCCAACCTGGCTTCT GGAGTCCCTGCTCGC

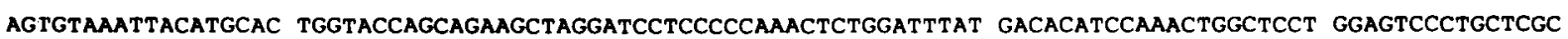
AGTGTAAGTTACATGCAC TGGTACCAGCAGAAGCCAGGATCCTCCCCCAAACCCTGGATTTAT GCCCCATCCAACCTGGCTTCT GGAGTCCCTGCTCGC AGTGTAAGTTACATGTAC TGGTACCAGCAGAaGCCAGGATCCTCCCCCAGACTCCTGATTTAT GACACATCCAACCTGGCTTCT GGAGTCCCTGTTCGC

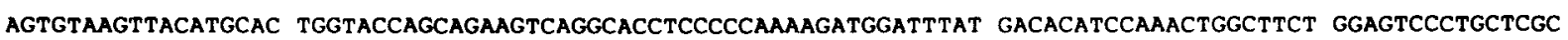
AGTGTAAGTTACATGCAG TGGTTCCAGCAGNAGTCAGGCACCTCCCCCAAAAGATGGATTTAT GACACATCCAAGCTGGNTTCT GGNGTCCCTACTCGC AGTGTAAGGTACATGAAC TGGTTCCAACAgAAGTCAGGCACCTCCCCCAAAAGATGGATTTAT GACACATCCAAACTGTCTTCT GGAGTCCCTGCTCGC AGTGTAAGTTACATGAAC TGGTTCCAGCAGAAGTCAGGCACCTCCCCCAAAAGATGGATTTAT GACACATCCAAACTGTCTTCT GGAGTCCCTCCTCGC ATTGTAAGTTACGTGCAG TGGTTCCAGCAGAAGTCAGGCACCTCCCCCAAAAGATGGATTTCT GACACATCCAAACTGCCTTCT GGAGTCCCTGCTCGC AGTGTAAGTTATATGAAC TGGTACCAGCAGAAGTCAGGCACCTCCCCCAAAAGATGGATTTAT GACACATCCAAACTGGCTTCT GGAGTCCCTGCTCGC AGTGTAAGTTACTTGCAG TGGTTCCAGCAGAAGTCAGGCACCTCCCCCAAAAGATGGATTTAT GACACATCCAAACTGGATTCT GGNGTCCCTGCTCGC AGTGTTAGTTACATGAAC TGGTTCCAGCAGAAGTCAGGCACCTCCCCCAAAAGATGGGTTTTT GCCACATCCAAACTGGNTTCT GGAGTCCCTGCTCGC AGTGTAAGTTACATGCAG TGGTTCCAGCAGAAGTCAGGCACCTCCCCCAAAAGATTGATTTTT TACACATCCAAACTGACTTCT GGAGTCCCTGCTCGC AGTGTAAGTTACATTCAG TGGTTCCAGCAGAAGCCAGGATCCTCCCCCAAACCCTGGATTCAT GCCACATCCAAGNTGGCTTCT GGAGTCCCTGCTCGC

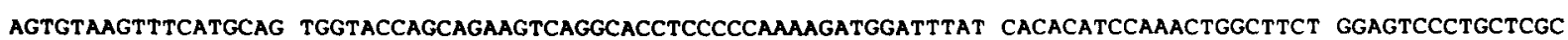

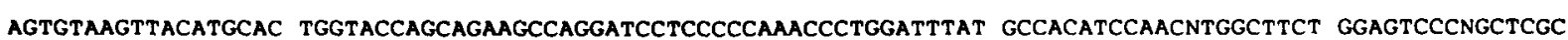


TTCAGTGGCAGTGGGTCTAGGACAGACTTCACCCTCACCATTAATCCTGTGGAGGCTGATGATGTTGCAACCTATTACTGT CAGCAAAGTAATGAGGATCCT TTCAGTGGCAGTGGGTCTGGGACAGACTTCACCCTCAACATCCATCCTGTGGAGGAGGAGGATGCTGCAACCTATTACTGT CAGCACAGTAGGGAGCTTCCT 004 TTCAGTGGCAGTGGGTCTGGGACAGACTTCACCCTCAACATCCATCCTGTGGAGGAGGAGGATACTGCAACATATTACTGT CAGCACAGTTGGGAGATTCCT 005 TTCAGTGGCAGTGGGTCTGGGACAGACTTCACCCTCAACATCCATCCTGTGGAGgAGgAAGATGCTGCAACCTATTACTGT CAGCAAATATTGAGGATCCT

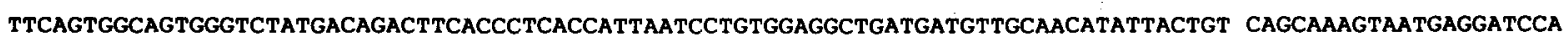
TTCAGTGGCAGTGGGTCTAGGACAGACTTCACCCTCACCATTGATCCTGTGGAGGCTGATGATGGTGCAACCTATTACTGT CAGCAAAATAATGAGGATCCG

008 TTTAGTGGCAGTGGGTCTGGGACAGACTTCAGCCTCAACATCCATCCTGTGGAGGAGGATGATATTGCAGTGTATTTCTGT CAGCAAAGTAGGAAGGTCCT 009 TTCAGTGGCAGTGGGTCTGGGACAGACTTCACCCTCAACATCCATCCTGTGGAGgAGgAGgATGCTGCAACCTATTACTGT CAGCACATTAGgGAGCT

010 TTTAGTGGCAGTgGatCAGgGaCAGATTTTACTCTTAGCATCAACAGTGTGGAGTCTGAAGATATTGCAGATTATTACTGT CAACAAAGTAATAGCTGGCCA 011 TTTAGTGGCAGTGGATCAGgGaCAGATTTTACTCCTAGCATCAACAGTGTGGAGTCTGAAGATATTGCAGAATATTACTGT CAACAAAGTTATAGGTGGCCA 012 TTTAGTGGCAGTGGATCAGGGACAGACTTTACTCTTAGCATCAACAGTGTGGAGTCTGAAGATGTTGCAGATTATTACTGT CAACAAACTAATAGCTGGCCG 013 TTCAGTGGCAGTGGATCAGGGACAGATTTCACTCTCAGTATCAACAGTGTGGAGACTGAAGATTTTGGATGTATTTCTGT CAACAGAGTAACAGCTGGCCT 014 TTCAGTGGCAGTGGATCAGGGACAGATTTCACTCTCAGTATCAACAGTGTGGAGACTGAAGATTTTGGAATGTATTTCTGT CAACAGAGTAACAACTGGCCT 015 TTCAGTGGCAGTGGATCAGGGACAGATTTCNCTCTCATTATCAACAATGTGGAGACTGAAGATTTTGGAATGTATTTCTGT CAACAGAGTAACAGCTGGCCT 016 TTCAGTGGCAGTGGATCAGGGACAGATTTCACTCTCAGTATCAACAGTGTGGAGACTGAAGATTTTGGAATGTATTTCTGT CAACAGAGTAACAGCTGGCCT 017 TTCAGTGGCAGTGGGTCTGGGACCTCTTATTCTCTCACAATCAGCAGCATGGAGGCTGAAGATGCTGCCACTTTTTACTGC CAGCAGTACAGTGGTTACCCA 018 TTCAGTGGCAGTGGGTCTGGGACCTCTTACTCTCTTACAATCAGCAGCGTGGAGGCCGAAGATGCTGCCACTTATTACTGC CAGCAGTGGAGTGGTTACCCA 019 TTCAGTGGCAGTGGgTCTGGgACCTCTTACTCTCTCACAATCAGCAGCGTGgAgGCTGAAGATGATGCAACTTATTACTGC CAGCAGTGGAGTGGTTACCCA TTCAGTGGCAGTGGGGCTGGGATCTCTTACTCTCTCACAATCAGCAGCATGGAGGCTGAAAATGATGCAACTTATTACTGC CAGCAGTGGAGTGGTTACCCA TTCAGTGGCAGTGGGTCTGGGACCTCTTACTCTCTCACAATCAGCAGCGTGGAGGCTGAaGATGCTGCCACTTATTACTGC CAGCAGTATCATAGTGACCCA TTCAGTGGCAGTGGGTCTGGGACCTCTTATTCTCTCACAATCAGCAGCATGGAGGCTGAAGATGCTGCCACTTATTACTGC CAGCAGTACAGTGGTTACCCA TTCAGTGGCAGTGGGNNTGTGACCTCTTACTCTCTCACAATTGGCACCATGGAGGCTNAAGATNTTGCCACTTACTACTGC CAGCAGGGTAGTAGTATACCG TTCAGTGGCAGTGGGTCTGGGACCTCTTACTCTCTCACAATCAGCAGTGTGGAGGCTGAAGATGCTGCCACTTATTACTGC CAGCAGTACAGTGGTTACCCA TTCAGTGGNAGTGGGTCTGGNACCTCTTACTCTCTCACAATTGGCACCATGGAGGCTGAaGATGTTGCCACTTACTACTGC CAGCAGGGTAGTAGTATACCG TTCAGTGGCAGTGGATCTGGGACCTCTTATTCTCTCACAATCAGCAGCATGGAGGCTGAAGATGCTGCCACTTATTACTGT CAACAGTGGAGTAGTTACCCA TTCAGTGGCAGTGGGTCTGGGACCTCTTACTCTCTCACAATCAGCAGCATGGAGGCTGAAGATGCTGCCACTTATTACTGC CACCAGTATCATCGTTCCCCA TTCAGTGGCAGTGGGTCTGGGaCATCTTTCTCTTTCACAATCAACAGCATGGAGGCTGAaGATGTTGCCACTTATTACTGT CAGCAAAGGAGTAGTTACCCA

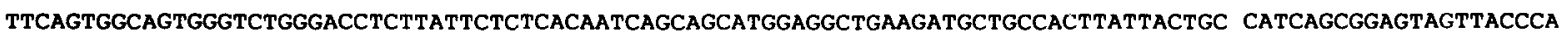
TTCAGTGGCAGTgGGTCTGGGACTCTTATTCTCTCACAATCAGCAGCATGgAgGGTGAGATGCTGCCACTTATTACTGC CAGCAGTTTACTAGTTCCCCA TTCAGTGGCAGTGGGTCTGGGACCTCTTACTCTCTCACAATCAGCAGTGTGGAGGCTGAAGATGCTGCCACTTATTACTGC CAGCAGTGGAGTGGTTACCAA TTCAGTGGCAGTGGGTCTGGGACCTCTTACTCTCTCACAATCAGCAGCATGGAGGCTGAAGATGCTGCCACTTATTACTGC CAGCAGTGGAGTAGTAACCCA TTCAGTGGCAGTGGGTCTGGGACCTCTTACTCTCTCACAATCAGCAGCATGGAGGCTGAAGATGCTGCCACTTATTACTGC CAGCAGTATCATAGTTACCCA

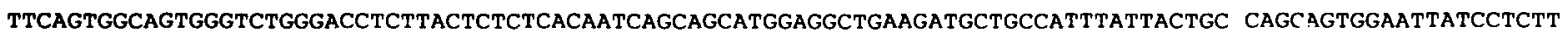
TTCAGTGGCAGTGGGTCTGGGACCTCTTATTCTCTCACAATCAGCAGCGTGAAGGCTGAAGATGCTGCCACTTATTACTGC CAGCAGTGGAGTAGTTCCCCA TTCAGTGGCAGTGGGTCTGGGACCTCTTACTCTCTCATAATCAGCAGCATGGAGGCTGAAGATGCTGCCACTTATTACTGC CATCAGCGGAGTAGTTACCCA TTCAGTGGCAGTGGGTCTGGGACCTCTTACTCTCTCACAATCAGCAGCATGGAGGCTGAAGATGCTGCCACTTATTACTGC CAGCAGTGGAGTAGTAACCCA TTCAGTGGCGAGTGGTCTGGGACCTCTTACTCTCTCGCAATCAGCAGAGTGGAGGCTGAAGATGCTGCCACTTATTACTGC CAGCAGTGGAatAGTAACCCA

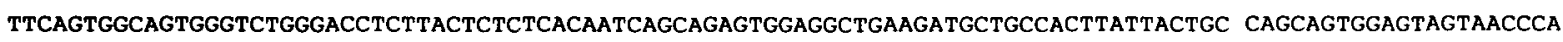
TTCAGTGGCAGTGGGTCTGGGACCTCTTACTCTCTCACAATCAGCAGCATGGAGGCTGAAGATGCTGCCTCTTATTTCTGC CATCAGTGGAGTAGTTACCCG TTCAGTGGCAGTGGGTCTGGGACCTCTTACTCTCTCACAATCAGCAGAGTGGAGGCTGAAGATGCTGCCACTTATTACTGC CAGCAGTGGAGTTTTAACCCA TTCAGTGGCAGTGGGTCTGCGACCTCTTACTCTCTCACAATCACCCGAATGCAGGCTGAAGATGCTGCCACTTATTACTGC CAGCAGTGGAGTAGTTACCCA TTCAGTGGCAGTGGGTCTGCGACCTCTTACTCTCTCACAATCACCAGCATGCAGGCTGAAGATGCTGCCACTTATTACTGC CAGCAGTGGAGTAGTAACCCG

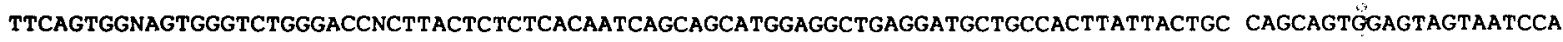
TTNAGTGGCAGTGGGTCTGGGACCTCTTNCTCTCTCACAATCAGCAGCATGGAGGNNGAAGATGNNGCCACTTATTACTGC CAGCAGTGGAGTAGTAATCCA TTCAGTGGCAGTNGGNCTGGGACCTCTTACTCTCTCACAATCAGCAGCATGGAGGCTGAAGATGCTGCCACTTATTACTGT CAGCAGTGGAATAGTAACCCA TTCAGTGGCAGTGGGTCTGGGACCTCTTACTCTCTCACAATCAGCAGCATGGAGGCTGAaGATGCTGCCACTTATTACTGC CAGCAGTGGACTAGTAACCCA TTCAGTGGCAGTGGGTCTGGGACCTCTTACTCTCTCACAATCAGCAGCATGGAGGCTGAAGATGCTGCCACTTATTACTGC CAGCAGTGGAATAGTAACCCG TTCAGTGGNAGTGGGTCTGGGACCTCTTACTCTCTCACAATCAGCAGCATGGAGGCTGAAGATGCTGCCACTTATTACTGC CAGCAGTGGACTAGTAACCCG TTCAGTGGCAGTGGGNCTGGGACCTCTTACTCTCTCACAATCAGCAGCATGGAGGCTGAaGATGCTGCCACTTATTACTGC CAGCAGTGGAGTAGTAACCCA

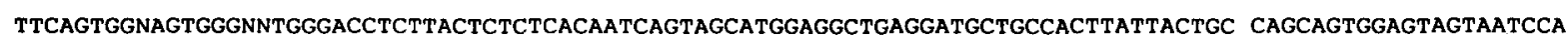
TTCAGTGGCAGTGGGTCTGGGACCTCTTACTCTCTCACAATCAGCAGAGTGGAGGCTGAAGATGCTGCCACTTTTTACTGC CAGCAGTGGAGTAGTAACCCG TTCAGTGGNAGTGGGTNTGGGACCTCTTACTCTCTCACAATCACCAGCATGGAGGCTGAAGATGCTGCCACTTATTACTGC CAGCAGTNGAGTGGNAATCCA TTCAGTGGCAGTGGGTCTGGGACCTCTTACTCTCTCACAATCAGCAGAGTGGAGGCTGAAGATGCTGCCACTTATTACTGC CAGCAGTGGAGTAGTAACCCA 
D

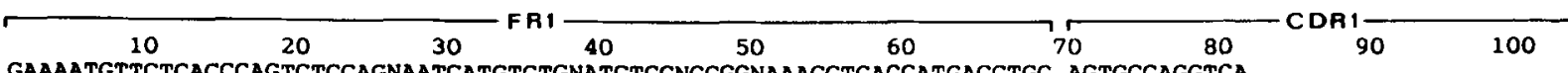

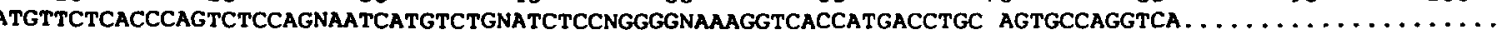

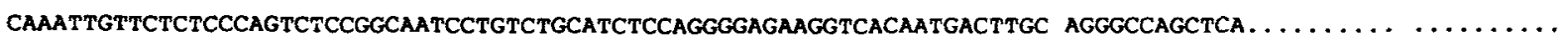

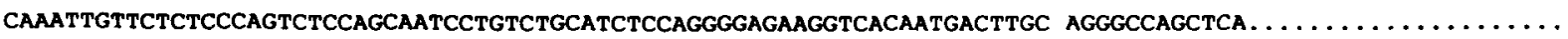

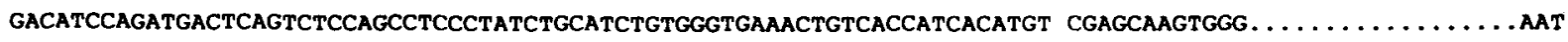

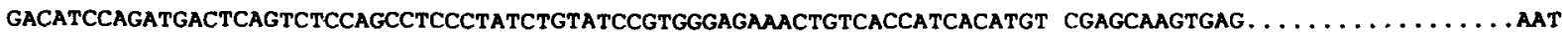

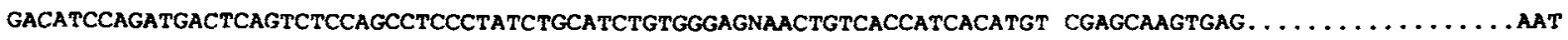

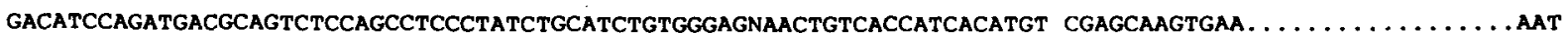

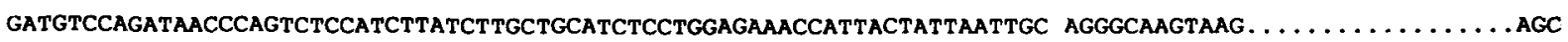

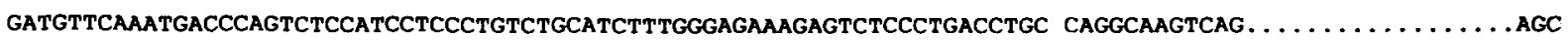

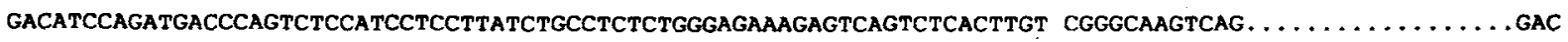

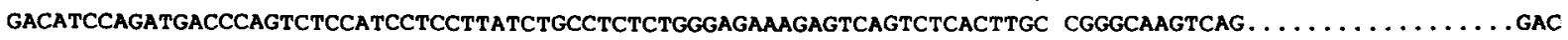

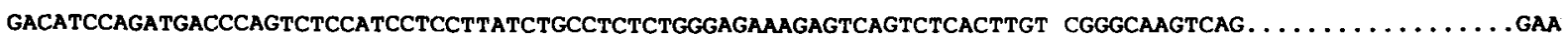

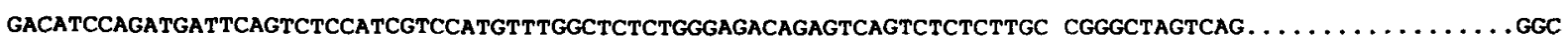

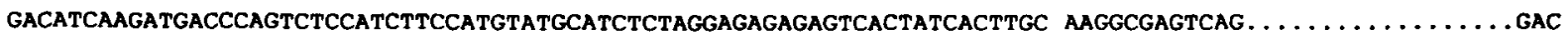

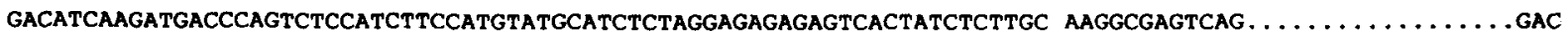

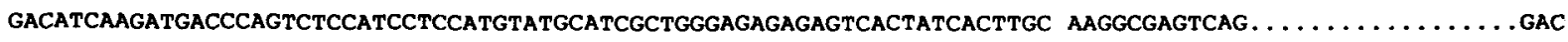

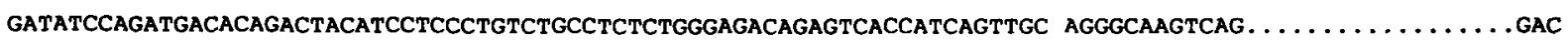

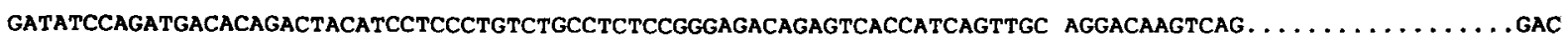

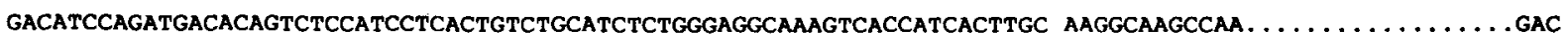

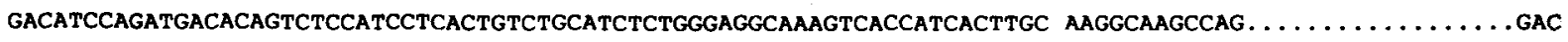
GATATTGTGATAACCCAGGATGAACTCTCCAATCCTGTCACTTCTGGAGAATCAGTTTCCATCTCCTGC AGgTCTAGTAAGAGTCTCCTATATAAG... GaT GaTATTGTGATGACGCAGGCTGCATTCTCCAATCCAGTCACTCTTGGAACATCAGCTTCCATCTCCTGC AGgTCTAGTAAGAGTCTCCTGCACAGT... AGT GATATTGTGATGACGCAGGCTGCATTCTCCAATCCAGTCACTCTTGGAACATCAGCTTCCATCTCCTGC AGGTCTAGTAAGAGTCTCCTACATAGT . . AaT GATATTGTGATGACTCAGGCTGCACCCTCTGTATCTGTCACTCCTGGAGAGTCAGTATTCATCTCCTGC AGGTCTAGTAAGAGTCTCCTGCATAGT... AAT

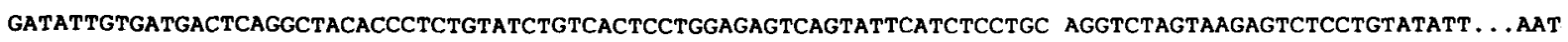
GATATTGTGATGACTCAGGCTGCACCCTCTGTACCTGTCACTCCTGGAGAGTCAGTATCCGTCTCCTGC AGGTCTAGTAAGAGTCTCCTGCATAGT ... AAT GATATTGTGATGACGCAGGCTGCCTTCTCCAATCCAGTCACTCTTGGAACATCAGCTTCCATCTCCTGC AGGTCTAGTAAGAATCTCCTACATAGT ... AAT GATGTTGTGATGACCCAAACTCCACTCTCCCTGCCTGTCAGTCTTGGAGATCAAGCCTCCATCTCTTGC AGATCTAGTCAGAGCCTTGTACACAGT ... AAT GATGTTTTGATGACCCAAACTCCACTCTCCCTGCCTGTCAGTCTTGGAGATCAAGCCTCCATCTCTTGC AGATCTAGTCAGAGCATtGTACATAGT ... AAT GATGCTGTGATGACCCAAACTCCACTCTCCCTGCCTGTCAGTCTTGGAGATCAAGCCTCCATCTCTTGC AGGTCTAGTCAGAGCCTTGAAAACAGT ... AAT GATGTTGTGGTGACTCAAACTCCACTCTCCCTGCCTGTCAGCTTTGGAGATCAAGTTTCTATCTCTTGC AGGTCTAGTCAGAGTCTTGCGACCAGT. . CAT GATGTTGTGATGACCCAAACTCCACTCTCCCTGCCTGTCAGCCTGGGAGATCAAGCCTCCATCTCTTGC AGATCTAGTCAGAGCATTGTACACAGT... AAT GATGCTGTGATGACCCAAACTCCACTCTCCCTGCCTGTCAGTCTTGGAGATCAAGCCTCCATCTCTTGC AGGTCTAGTCAGAGCATTGAAAACAGT... AAT GATATTGTGATGACCCAAACTCCACTCTCCCTGCCTGTCAGTCTTGGAGATCAAGCCTCCATCTCTTGC AGATCTAGTCAGAGCATTGTAATCAGT ... AAT

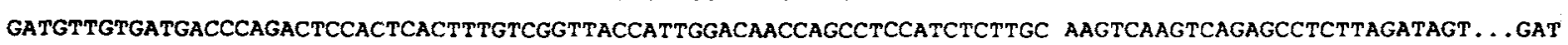
GACATTGTGATGACACAGTCTCCATCCTCCCTGGCTATGTCAGTAGGACAGAAGGTCACTATGAGCTGC AagTCCAGTCAGAGCCTTTTAAATAGTAGCAAT GGCATTGTGATGTCACAGTCTCCATCCTCCCTAGCTGTGTCAGTTGGAGAGAAGGTTACTATGAGCTGC AaGTCCAGTCAGAGCCTTTTCTATAGTAGCAAT GACATTGTGATGACACAGTCTCCATCCTCCCTGACTGTGACAGCAGGAGAGAAGGTCACTATGAGCTGC AAGTCCAGTCAGAGTCTGTTAAACAGTGGAAAT GACATTGTGATGACACAGTCTCCATCCTCCCTGAGTGTGTCAGCAGGAGAGAAGGTCACTATGAGCTGC AAGTCCAGTCAGAGTCTGTTAAACAGTGGAAAT AACATTATGATGACACAGTCGCCATCATCTCTGGCTGTGTCTGCAGGAGAAAAGGTCACTATGAGCTGT AAGTCCAGTCAAAGTGTTTTATACAGTTCAAAT GACGTTGTGATGTCACAGTCTCCATCCTCCCTGGCTGTGTCAGCAGGAGAGAAGGTCGCTGTGAGCTGC AAATCCAGTCAGAGTCTGTCTACAGTAGAACCC GNCATTGTGATGACACAGTCTCCNCNCTCCCTGAGTGTGTCAGCAGGANNNAAGGTCACTATGAGCTGT AAGTCCAGTCAGNGTCTGNTTAACAGTGNAGTC GACATTGTGATGACTCAGTCTCCAACTTTCCTTGCTGTGACAGCAAGTAAGAaGgTCACCATTAGTTGC ACTGCNTCTGAGAGCCTTTATTCAAGCAAACAC

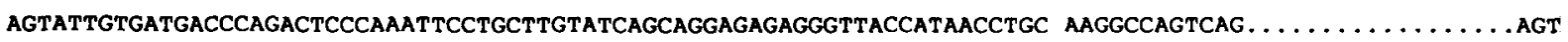

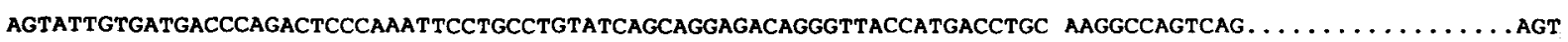
gacattgtgatgacccagtctcacaAattcatgtccacatcagtaggagacagggtcagcatcacctgc aaggccagtcag................

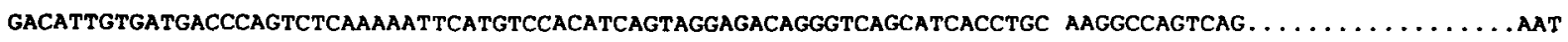

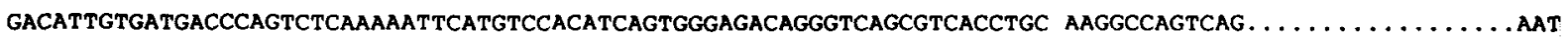

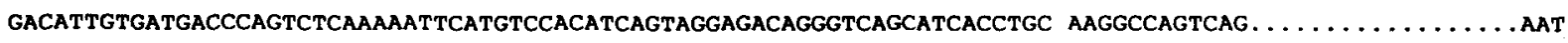

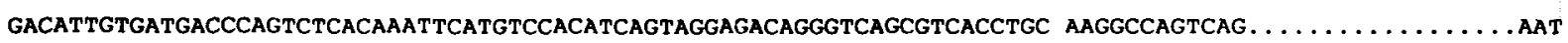

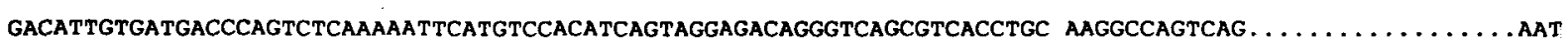

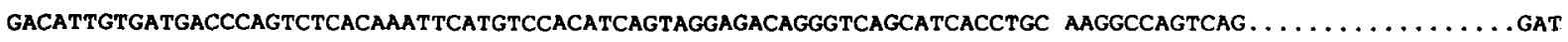

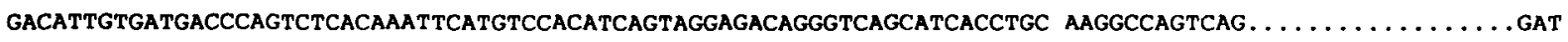

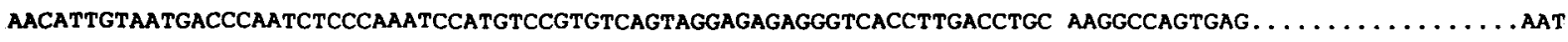

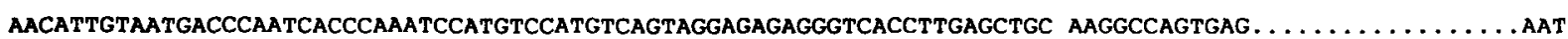




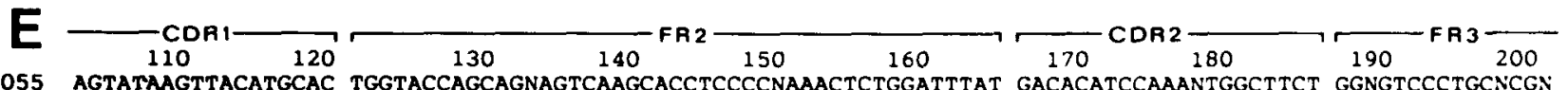

055 AGTATAAGTACATGCAC TGGTACCAGCAGNAGTCAAGCACCTCCCCNAAACTCTGGATTTAT GACACATCCAAANTGGCTTCT GGNGTCCCTGCNCGN

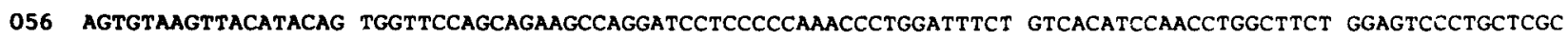

057 AGTGTAAGTTACATACAC TGGTACCAGCAGAAGCCAGGATCCTCCCCCAAACCCTGGaTTTAT GCCACATCCAACCTGGCTTCT GGAGTCCCTGTTCGC

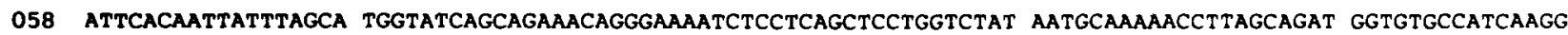

059 ATTTACAGTAATTGGCA TGGTTATTCAGCAGAAACAGgGAAAACCCCCCCAGCTTGGTCTAT GCTGCAACAAACTTAGCAGAT GGTGTGCCATCAAGG

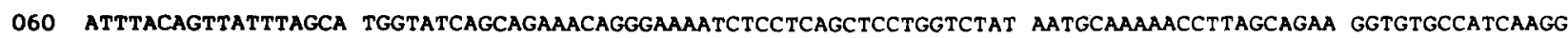

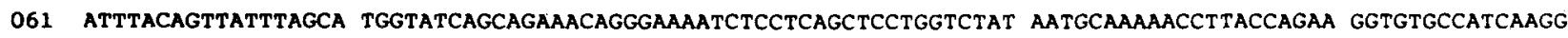

062 ATTAGCAAATATTTAGCC TGGTATCAAGAGAAACCTGGGAAAACTAATAAGCTTCTTATCTAC TCTGGATCCACTTTGCAATCT GGAATTCCATCAAGG

063 ATTAACAATTTTTTAAAA TGGTTTCAGCAAACACTGGGGAAAACTGCTAGGCTCTTGATCTAT GGTGCAAACAAATTGGAAGAT GGGGTCCCTTCAAGG

064 ATTGGTAGTAGCTTAAAC TGGCTTCAGCAGGAACCAGATGGAACTATTAAACGCCTGATCTAC GCCACATCCAGTTTAGATTCT GGTGTGCCCAAAAGG

065 ATTCATGGTTATTTAAAC TTGTTTCAGCAGAAACCAGGTGAAACTATTAAACACCTGATCTAT GAAACATCCAATTTAGATTCT GGTGTCCCAAAAAGG

066 ATTAGTGGTTACTTAAGC TGGCTTCAGCAGAAACCAGATGGAACTATTAAACGCCTGATCTAC GCCGCATCCACTTTAGATTCT GGTGTCCCAAAAAGG

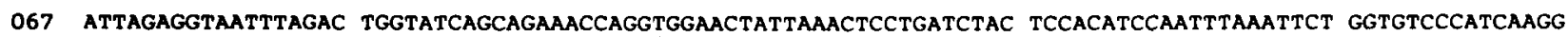

068 ATTAATAGCTATTTAAGC TGGTTCCAGCAGAAACCAGGGAAATCTCCTAAGACCCTGATCTAT CGTGCAAACAGATTGGTAGAT GGgGTCCCATCAAGG

069 ATTAATAGCTATTTAACC TGGTTCCAGCAGAAACCAGGGAAGTCTCCTAAGACCCTGCTCTAT CGTACAAAGAGATTGGTAGAT GGGGTCCCATCAAGG

070 ATTAAAAGTATTTAAGC TGGTACCAGCAGAAACCATGGNAATCTCCTAAGACCCTGATCTAT TATGCAACAAGCTTGGCAGAT GGGGTCCCATCAAGA

071 ATTAGCAATTATTTAAA TGGTATCAGCAGAAACCAGATGGAACTGTTAAACTCCTGATCTAC TACACATCAAGATTACACTCA GGAGTCCCATCAAGG

072 ATTAGCAATTTTTATAC TGgTTTCAGCAGAAATCAGATGGAACTGTTAAACTCCTGATCTAC TACACCTCAAGATAACACTCA GGAGTCCCATCAAGg

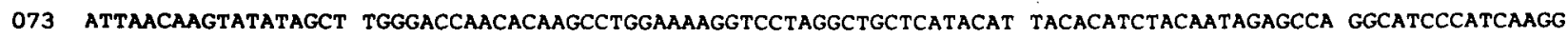

074 ATTAACAAGTATTTAGCT TGGTACCAACACAAGCCTGGAAAAGGTCCTAGgCTGCTCATACAT TACACATCTACATTACAGCCA GGCATCCCATCAAGG

075 GGgAagACATACTTGAAT TGGTTTCTGCAGAGACCAGGACAATCTCCTCAGCTCCTGATCTAT TTGATGTCCACCCGTGCATCA GgAGTCTCAGACCGG

076 GGCAACACTTACTTGTAT TGGTTCCTGCAGAAGCCAGGCCAGTCTCCTCAGCTCCTGATATAT TATATCTCCAACCTTGCCTCA GGAGTCCCAGACAGG

077 GGCATCACTTATTTGTAT TGGTATCTGCAGAAGCCAGGCCAGTCTCCTCAGCTCCTGATTTAT CAGATGTCCAACCTTGCCTCA GGAGTCCCAGACAGG

078 GGCAACACTTACTTGTAT TGGTACCTACAGAGGCCAGGCCAGTCTCCTCAGCTCCTGATATAT CGGATGTCCAACCTTGCCTCA GGAGTCCCAGACAGG

079 GGCAACACTTACTTGTAT TGGTACCTACAGAGGCCAGGCCAGTCTCCTCAACTCCTGATATAT CGGATGTCCTACCTTGCCTCA GGAGTCCCAGACAGG

080 GGCAACACTTACTTGTAT TGGTTCCTGCAGAGgCCAGGCCAGTCTCCTCAGCTCCTGATATAT CGGATGTCCAACCTTGCCTCA GGAGTCCCAGACAGG

081 GGCATCACTTTTTTATAT TGGTATCTCCAGAGGCCAGGCCAGTCTCCTCAGCTCCTGATATAT CGGGTGTCCAATCTGGCCTCA GGAGTCCCAAACAGG

082 GGAAACACCTATTTACAT TGGTACCTGCAGAaGCCAGGCCAGTCTCCAAAGCTCCTGATCTAC AAAGTTTCCAACCGATTTTCT GGGGTCCCAGACAGG

083 GGAAACACCTATTTAGAA TGGTACCTGCAGAAACCAGGCCAGTCTCCAAAGCTCCTGATCTAC AAAGTTTCCAACCGATTTTCT GGGGTCCCAGACAGG

084 GGAAACACCTATTTGAAG TGGTACCTCCAGAAACCAGGCCAGTCTCCACAGCTCCTGATCTAC AGGGTTTCCAACCGATTTTCT GGGGTCCTAGACAGG

085 GGGATCACCTATTTGTCT TGGTACCTGCACAAGCCTGGCCAGTCTCCACAGCTCCTCATCTAT GGGATTTCCAACAGATTTTCT GGGGTGCCAGACAGG

086 GGAAACACCTATTTATAT TGGTACCTGCAGAAACCAGGCCAGTCTCCAAAGCTCCTGATCTAC AGGGTTTCCAACCGATTTCT GGGGTCCCAGACAGG

087 GGAAACACCTATTTGAAC TGGTACCTCCAGAAACCAGGCCAGTCTCCCAGGCTCCTGATCTAC AGGGTTTCCAACCGATTTTCT GGGGTCCTAGACAGG

088 GGGTTCACCTATTTAGAA TGGTACCTGCAGAAACCAGGNNNNNNNNNAAAGCTCCTGATATAT GGGATTTCCAACCGATTTTCT GGGGTCCCAGACAGG

089 GgAAAGACATATTTGAAT TGGTTGTTACAGAGGCCAGGCCAGTCTCCAAAGCGCCTAATCTAT CTGGTGTCTAAACTGGACTCT GGAGTCCCTGACAGG

090 CAAAAGAACTATTTGGCC TGGTACCAGCAGAAACCAGGACAGTCTCCTAAACTTCTGGTATAC TTTGCATCCACTAGGGAATCT GGGTCCCTGATCGC

091 CAAAAGAACTCTTTGGCC TGGTACCAGCAGAGACCAGGGCAGTCTCCTAAACTGCTGATTTAC TGGGCATCCACTAGGGAACT GGGGTCCCTGATCGC

092 CCGAAGAACTACTTGACC TGGTACCAGCAGAAACCAGGGCAGCCTCCTAAACTGTTGATCTAC TGGGCATCCACTAGGGAATCT GGGGTCCCTGATCGC

093 CAAAAGAACTACTTGGCC TGGTACCAGCAGAAACCAGGGCAGCCTCCTAAACTGTTGATCTAC GGGGCATCCACTAGGGAATCT GGGGTCCCTGATCGC

094 CAGAAGAACTACTTGGCC TGgTACCAGCAGAAACCAGGGCAGTCTCCTAAACTGCTGATCTAC TGGGCATCCACTAGGGAATCT GGAGTCCCTGATCGC

095 GAAAGAAGCTACTTGGCT TGGTACCAGCAGAAACCAGGGCAGTCTCCTAAACTGCTGATCTAC TGGGCATCCACTAGGGAATCT GGGGTCCCTGATCGC

096 AAAAGAACTAACTTGGCC TGGTACCANAAGAAACCAGGGCAGCCTCCNAAACTGTTGATCTCC GTGGATGCGCGACCCNCACAC GGAGTCCCTGATCGC

097 AAGGTGCACTACTTGGCT TGGTACCAGAAGAAACCAGAGCAATCTCCTAAACTGCTGATATAC GGGGCATCCAACCGATACATT GGGGTCCCTGATCGC

098 GTGAGTAATGATGTAGCT TGGTACCAACAGAAGCCAGGGCAGTCTCCTAAACTGCTGATATAC TATGCATCCAATCGCTACACT GGAGTCCCTGATCGC

099 GTGGGTAATAAGTAGCC TGGTACCAACAGAAGCCAGGACAGTCTCCTAAACTGCTGATATAC TATGCATCCAATCGCTACACT GGAGTCCCTGATCGC

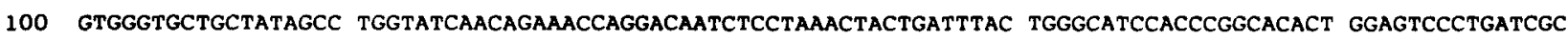

101 GTGGGTACTGCTGTAGCC TGGTATCAACAGAAACCAGGACAATCTCCTAAACTACTGATTTAC TCGGCATCCAATCGGTACACT GGAGTCCCTGATCGC

102 GTGGTCACTAATGTAGCC TGGTATCAACAGACACCAGgACAATCTCCTAAAGCACTGATTTAC TCGgCATCCTACCGgTACAGT gGaGTCCCTGATCGC

103 GTTCGTACTGCTGTTGCC TGGTATCAACAGAAACCAGGGCAGTCTCCTAAAGCACTGATTTAC TTGGCATCCAACCGGTACACT GGAGTCCCTGATCGC

104 GTGGgTACTAATGTAGCC TGgTATCAACAGAAACCAGgGCAATCTCCTAAAGCACTGATTTAC TCGgCATCCTACCGGTACAGT GGAGTCCCTGATCGC

105 GTGGgTACTAATGTAGCC TGGTATCAGCAGAAACCAGgGCAATCTCCTAAAGCACTGATTTAC TCGgCATCCTACCGGTACAGT gGaGTCCCTGATCGC

106 GTGAGTACTACTGTGGCC TGGTATCAGCAGAAACCAGGGCAATCTCCTAAACTACTGATTTAT TCGGCATCCTACCGGTACACT GGAGTCCCTGATCGC

107 GTGAGTACTGCTGTAGCC TGGTATCAACAGAAACCAGGACAATCTCCTAAACTACTGATTTAC TCGGCATCCTACCGGTACACT GGAGTCCCTGATCGC

108 GTGGTTACTTATGTTTCC TGGTATCAACAGAAACCAGAGCAGTCTCCTAAACTGCTGATATAC GGGGCATCCAACCGGTACACT GGGGTCCCCGATCGC

109 GTGGgTACTTATGTATCC TGgTATCAACAGAAACCAGAGCAGTCTCCTAAACTGCTGATATAC GGgGCATCCAACCGGTACACT GGgGTCCCCGATCGC 
5
210

220

230

250

260

270

280 290

300 TTCAGTGGNAGTGGGNCTGGNAACTCTTACTCTCTCACGATCAGCAGCATGGAGGCNGAAGATGTTGCCACTTATTACTGT TTTCNGGGGAGTGGGTACCCA TTCAGTGGNAGTGGGTCTGGGACCTCTTACTCTCTCACAATCAGCAGAGTGGAGGCTGAAGATGCTGCCACTTATTACTGC CAGCAGTGGAGGAGTAACCCA TTCAGTGGAAGTGGGTCTGGGACCTCTTACTCTCTCACAATCAACAGAGTGGAGGCTGAAGATGCTGCCACTTATTACTGC CAGCAGTGGAGTAGTAACCCA TTCAGTGGCAGTGGATCAGGAACACAATATTCTCTCAAGATCAACAGCCTGCAGCCTGAAGATTTTGGGAGTTATTACTGT CAACATTTTTGGAGTACTCCT TTCAGTGGCAGTGGATCAGGAACACAATATTCTCTCAAGATCAACAGCCAGCAGCCGGAGGATTTTGGGAGTTATTACTGT CAACATTTTTGGAGTGCTCCT TTCAGTGGCAGTGGATCAGGCACACAGTTTTCTCTGAAGATCAACAGCCTGCAGCCTGAAGATTTTGGGAGTATTACTGT CAACATCATTATGTTACTCCG TTCAGTGGCAGTGGATCAGGCACACAGTTTTCTCTGAAGATCAACAGCCTGCAGCCTGAAGATTTTGGGAGTTATTACTGT CAGCATCATTATGGTCCTCCG TTCAGTGGCAGTGGATCTGGTACAGATTTCACTCTCACCATCAGTAGCCTGGAGCCTGAAGATTTTGCAATGTATTACTGT CAACAGCATAATGAATACCCG TTCAGTGGAACTGGATATGGGACAGATTTCACTTTCACCATCAGCAGCCAGGAGGAAGAAGATGTGTCAACTTATTTCTGT CTACAGCATAGGTATCTCCCT TTCAGTGGCAGTAGGTCTGGGTCAGATTATTCTCTCACCATCAGCAGCCTTGAGTCTGAAGATTTTGTAGACTATTACTGT CTACAATATGCTAGTTCTCCT TTCAGTGGCAGTAGGTCTGGGTCAGATTATTCTCTCATTATCGGCAGCCTTGAGTCTGAAGATTTTGCAGACTATTACTGT CTACAATATGCTAGTTCTCCT TTCAGTGGCAGTAGGTCTGGGTCAGATTATTCTCTCACCATCAGCAGCCTTGAGTCTGAAGATTT TGCAGACTATTACTGT CTACAATATCTTAGTTATCCG TTCAGTGGCAGTGGGTCTGGGTCAGATTATTCTCTCACCATCAGCAGCCTAGAGTCTGAAGATTTTGCAGACTATTACTGT CTACAGCGTAATGCGTATCCG TTCAGTGGCAGTGGATCTGGGCAAGATTATTCTCTCACCATCAGCAGCCTGGAGTATGAAGATATGGGAATTATTATTGT CTACAGTATGATGAGTTTCCT TTCAGTGGCAGTGGATCTGGGCAAGAATATTCTCTCACCATCAGCAGCCTGGAGTATGAAGATATGGGAATTTATTTTTGT CTTCAGTATGATGAATTTCTT TTCAGTGGCAGTGGATCTGGGNAAGATTATTCTCTAACCATCAGCAGCCTGGAGTCTGACGATACAGCAACTTATTACTGT CTACAGCATGGTGAGAGCCCT TTCAGTGGCAGTGGGTCTGGAACAGATTATTCTCTCACCATTAGCAACCTGGAGCAAGAAGATATTGCCACTTACTTTTGC CAACAGGGTAATACGCTTCCT TTCAGTGGCAGTGGGTCTGGAACAGATTATTCTTTCACCATTAACAACCTGGAGTAAGAAGATGTCGCCACTTATTCTTGA CAACAGGGTATATT TTCAGTGGAAGTGGGTCTGGGAGAGATTATTCCTTCAGCATCAGCAACCTGGAGCCTGAAGATATTGCAACTTATTATTGT CTACAGTATGATAATCTGTAC TTCAGTGGAAGTGGGTCTGGGAGAGATTATTCCTTCAGCATCAGCAACCTGGACGCGGAAGAGATTGCAACTTATTATTGT CTACAGTATGATAGTCTGTAC TTTAGTGGCAGTGGGTCAGGAACAGATTTCACCCTGGAAATCAGTAGAGTGAAGGCTGAGGATGTGGGTGTGTATTACTGT CAACAACTTGTAGAGTATCCT TTCAGTGGCAGTGGGTCAGGAACTGATTTCACACTGAGAATCAGTAGAGTGGAGGCTGAGGATGTGGGTGTTTATTACTGT ATGCAAGGTCTAGAATATCCT TTCAGTAGCAGTGGGTCAGGAACCGACTTCACACTGAGAATCAGCAGAGTGGAGGCTGAGGATGTGGGTGTTTATTACTGT GCTCAAAATCTAGAACTTCCT TTCAGTGGCAGTGGgTCAGGAACTGCTTTCACACTGAGAATCAGTAGAGTGGAGGCTGAGGATGTGGGTATTTATTATTGT ATGCAACATCTAGAATATCCT TTCAGTGGCAGTGGGTCAGGAACTGCTTTCACACTGAGAATCAGTAGAGTGGAGGCTGAGGATGTGGGTATTTATTATTGT ATGCAACATCTAGAATATCCT TTCAGTGGCAGTGGGTCAGGAACTGCTTTCACACTGAGAATCAGTAGAGTGGAGGCTGAGGATGTGGGTGTTTATTACTGT ATGCAACATCTAGAATATCCG TTCAGTGGCAGTGAGTCAGGAACTGATTTCACACTGAGAATCAGCAGAGTGGAGGCTGAGGATGTGGGTGTTTATTACTGT GCTCAACTGCTAGAACTCCC TTCAGTGGCAGTGGATCAGGGACAGATTTCACACTCAAGATCAGCAGAGTGGAGGCTGAGGATCTGGGAGTTTATTTCTGC TCTCAAAGTACACATGTTCCT TTCAGTGGCAGTGGATCAGgGaCAGATTTCACACTCAAGATCAGCAGAGTGGAGgCTGAGgATCTGGGAGTTATTACTGC TTTCAAGGTTCACATGTTCCT TTCAGTGGTAGTGGATCAGGGACAGATTTCACACTGAAAATCAGCAGAGTGGAGGCTGAGGATTTGGGAGTTTATTTCTGC CTCCAAGTTACACATGCTCCT TTCAGTGGCAGTGGTTCAGGGACAGATTTCACACTCAAGATCAACACAATAAAGCCTGAGgACTTGgGAATGATTACTGC TTACAAGGTTCACATCAGCCG TTCAGTGGCAGTGGATCAGGGACAGATTTCACACTCAATATCAGCAGAGTGGAGGCTGAGGATATGGGAGTTTATTACTGC TTTCAAGGTACACATGTTCCT TTCAGTGGTAGTGGATCAGGGACAGATTTCACACTGAAAATCAGCAGAGTGGAGGCTGAGGATTTGGGAGTTTATTTCTGC CTCCAAGTTACACATGTCCCG TTCAGTGGCAGTGGATCAGGGACAGATTTCACACTCAAGATCAGCAGAGTGGAGGCTGAGGATGTAGGAATTTATTACTGT TTTCAAGGTATACATGTTCCG TTCACTGGCAGTGGATCAGGGACAGATTTCACACTGAAAATCAGCAGAGTGGAGGCTGAGGATTTGGGAGTTTATTATTGC TGGCAAGGTACACATTTTCCT TTCATAGGCAGTGGATCTGGGACAGATTTCACTCTTACCATCAGCAGTGTGCAGGCTGAAGACCTGGCAGATTACTTCTGT CAGCAACATTATAGCACTCCG TTCACAGGCAGTGGATCTGGGaCAGATTTCACTCTCACCATCAGCAGTGTGAAGGCTGAaGACCTGGCAGTTTATTACTGT CAGCAATATTATAGCTATCCG TTCACAGgCAGTGGATCTGGAACAGATTTCACTCTCACCATCAGCAGTGTGCAGGCTGAAGACCTGGCAGTTTATTACTGT CAGAATGATTATAGTTATCCG TTCACAGGCAGTGGATCTGGAACCGATTTCACTCTTACCATCAGCAGTGTGCAGGCTGAAGACCTGGCACTTTATTACTGT CAGAATGATCATACTTATCCG TTCACAGGCAGTGGATCTGgGaCAGATTTPACTCTTACCATCAGCAGTGTACAAGCTGAaGACCTGGCAGTTTATTACTGT CATCAATACCTCTCCTCG TTCACGGGCAGTGGATCTGGGACAGATTTCACTCTCACCATCAGCAGTGTGCGGGCTGAAGACCTGGCAGTTTATTACTGC AAGAATCTTATGGATCTTCCC

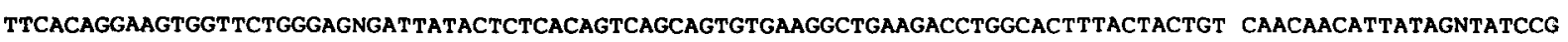
TTCACAGGCAGTGGATCTGGGACAGATTTCACTCTGACCATCAGCAGTGTACAGGTTGAAGACCTCACACATTATTACTGT GCACAGTTTTACAGCTATCCT TTCACTGGCAGTGGATATGGGACGGATTTCACTTTCACCATCAGCACTGTGCAGGCTGAAGACCTGGCAGTTTATTTCTGT CAGCAGGATTATAGCTCTCCT TTCACTGGCAGTGGATCTGGGACAGATTTCACTTPCACCATCAGCAGTGTGCAGGTTGAAGACCTGGCAGTTTATTTCTGT CAGCAGCATTATAGCTCTCCG TTCACAGGCAGTGGATCTGgGaCAGATTTCACTCTCACCATTAGCAATGTGCAGTCTGATGACTTGGCAGATTATTTCTGT CAACAATATAGCGGGTATCCT TTCACAGGCAGTGGATCTGGGACAGATTTCACTCTCACCATCAGCAATATGCAGTCTGAAGACCTGGCAGATTATTTCTGC CAGCAATATAGCAGCTATCCT TTCTCAGgCAGTGGaTCTGGGaCAGATTTCACTCTCACCATCAGCAATGTGCAGTCTGGaGaCTTGGCAGAGTATTTCTGT CAGCAATATAACAGCTATCCT TTCACAGGCAGTGGATCTGGGACAGATTTCACTCTCACCATTACCAATGTGCAATCTGAAGACCTGGCAGATTATTTCTGT CTGCAACATTGGAATTATCCG TTCACAGGCAGTGGaTCTGGGACAGATTTCACTCTCACCATCAGCAATGTGCAGTCTGAaGACTTGGCAGAGTATTTCTGT CAGCAATATAACAGCTGTCCA TTCACAGGCAGTGGATCTGGGACGGATTTCACTCTCACCATCAGCAATGTGCAGTCTGAAGACTTGGCAGTGTATT TCTGT CAGCAATATAACAGCTATCCG

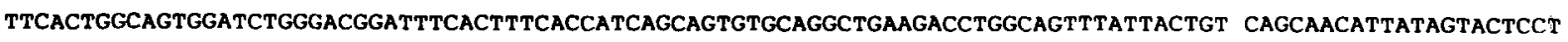
TTCACTGGCAGCGGATCTGGGACGgATTTCACTTTCACCATCAGCAGTGTGCAGGCTGAAGACCTGGCAGTTTATTACTGT CAGCAACATTATAGTACTCCG TTCACAGGCAGTGGATCTGCAACAGATTTCACTCTGACCATCAGCAGTGTGCAGGCTGAAGACCTTGCAGATTATCACTGT GGACAGGGTTACAGCTATCCG TTCACAGGCAGTGGATCTGCAACAGATTTCACTCTGACCATCAGCAGTGTGCAGTCTGAaGACCTTGCAGATTATTTCTGT GGACAGAGTTACAGCTATCCC 
similar members from a single $V_{k}$ gene family $\left(V_{k} 4 / 5\right)$ were present in different groups (IV and VI).

Organization of $V_{k}$ proteins into subgroups using $<13$ mismatches up to Trp35 as a criterium (Potter et al. 1982) better reflected primary structure similarities, although such organization frequently led to multiple assignments, in which cases only a single assignment for the sequence representing the best match was included (Table 1). Moreover, as will be shown below, this classification repeatedly failed to adequately reflect overall similarity at the nucleic acid sequence level. Finally, some sequences (discussed below) could not be assigned unambiguously to any existing $V_{k} \operatorname{Trp}$ subgroup.

We then determined whether $V_{k}$ nucleic acid sequences could be organized into gene families (analogous to $V_{H}$ genes), and how such families related to $\mathrm{V}_{\mathrm{k}}$ protein groups and subgroups. For this purpose, all $V_{k}$ genes in the data bank were arranged in groups of $>80 \%$ sequence similarity, which were termed $V_{k}$ gene families. The characteristics of these families and their relationship to $\mathrm{V}_{\mathrm{k}}$ protein groups and subgroups are detailed below. A quick summary outlining how the different classifications correspond to each other is presented in Table 2.

$V_{k} 21$ gene family. All $V_{k} 21$ genes fulfilled the criteria for a typical $V$ gene family, i. e., all members were $>80 \%$ similar (mostly $>90 \%$ ) and differed from all other $V_{k}$ sequences by at least $25 \%$. This gene family corresponded completely to protein subgroup $\mathrm{V}_{\mathrm{k}} 21$ which, in turn, coincided with $V_{k}$ protein group III. Five germline genes have been cloned (Heinrich et al. 1984) and approximately ten expressed sequences have been published. $V_{k} 21$ genes were used in response to influenza hemagglutinin (Clarke et al. 1985, Meek et al. 1989) and major histocompatibility complex class II antigens (Devaux et al. 1985), and encoded some lupus-associated autoantibodies (Shlomchik et al. 1987c). The P3-X63-Ag8.653 myeloma line, a derivative of the MOPC21 myeloma that has lost the ability to express Ig heavy and light chain proteins and is frequently used in hybridoma technology (Kearney et al. 1979), also expressed a non-functional $V_{k} 21$ mRNA
(Strohal et al. 1987). With the exception of an MRLlpr/lpr rheumatoid factor (RF, anti-Ig) $\mathrm{V}_{\mathrm{k}}$ sequence (AM12; Shlomchik et al. 1987c), which differed from all known $V_{k} 21$ germline genes by $>30 \mathrm{bp}$ and may have derived from an unknown germline gene, all other expressed sequences were very similar to, and hence probably derived from, known $V_{k} 21$ germline genes. RFLP (Kofler et al. 1989) and gene cloning analyses (Heinrich et al. 1984) suggested an estimated 6 to $13 V_{k} 21$ germline genes in the genome of most inbred strains of mice.

Finally, an incomplete $V_{k} 21$ sequence (VM201, Meek et al. 1989), which was therefore not included in our data bank, should be mentioned as it lacked two codons in CDR-1 in comparison to other $\mathrm{V}_{\mathrm{k}} 21$ sequences. Unless caused by somatic events, this would make the corresponding germline gene the only $V_{k}$ gene with 37 codons up to Trp35.

$V_{k} 23$ gene family. Similar to $\mathrm{V}_{\mathrm{k}} 21, \mathrm{~V}_{\mathrm{k}} 23$ sequences were well separated from all other $V_{k}$ sequences, and formed a gene family that corresponded entirely to its protein counterpart, the $V_{k} 23$ subgroup (protein group $V$ ). One germline gene has been reported (Pech et al. 1981) that was subsequently observed in RFs from BALB/c mice (Shlomchik et al. 1987a), and that probably encoded an $\left(\mathrm{NZB} \times \mathrm{NZW} \mathrm{F}_{1}\right.$ RNA-specific autoantibody (Eilat et al. 1988).

Additional $V_{k} 23$ genes, more distant from the above germline gene but closely related to each other, possibly derived from a second $V_{k} 23$ germline gene and encoded nitrophenyl-specific anti-idiotypes (Sablitzky and Rajewsky 1984) and a creatine-kinase-specific antibody (Buckel et al. 1987). A nonfunctional $\mathrm{V}_{\mathrm{k}} 23$ member was cloned from an MRL/n RF-producing hybridoma and might correspond to another $V_{k} 23$ (pseudo) gene (Kofler et al. 1989). Our previous RFLP analyses suggested the presence of four to eight $V_{k} 23$ germline genes in the genome of most inbred strains of mice. However, this may represent an over-estimate due to cross-hybridization of the more conserved $3^{\prime}$ portion of the $\mathrm{V}_{\mathrm{k}} 23$ probe with $\mathrm{V}_{\mathrm{k}} 1$ sequences (Kofler et al. 1989, and below).

Fig. 1. Nucleic acid sequences of $109 V_{k}$ genes contained in the $V_{k}$ database. Dots have been introduced to maximize homology; $N$, undetermined nucleotides; CDR, complementarity determining region; FR, frame work region (according to Kabat et al. 1987). Codes of $V_{k}$ genes: $1=V_{k} 21 B$, $2=V_{k} 21 C, 3=V_{k} 2 I E, 4=V_{k} 1.6 k b, 5=V_{k} 18 \mathrm{~kb}, 6=H 37-85,7=A M 10,8=A M 12,9=A g 8.653 k-, 10=L 7,11=T 2,12=D 444,13=M R L / n-R F 33 B$, $14=A 8 / 4,15=A 20 / 44,16=M A K 33,17=H 1,18=R 11,19=R 1,20=L 8,21=$ MRL-Histone $7,22=M R L-D N A 22,23=N Q 10-4.6 .1,24=N Q 11-1.18$, $25=N Q 22-87.1,26=A 9,27=37 A 4,28=R 2,29=R 9,30=R 13,31=H 2,32=H 3,33=H 4,34=H 6,35=H 8,36=H 9,37=H 13,38=L 6,39=70 Z / 3$, $40=A M I, 41=2 H 7,42=N Q 2-6.1,43=N Q 2-48.2 .2,44=N Q 10-12.4 .6,45=N Q 10-12.5,46=N Q 10-15.3,47=N Q 11-7.12,48=N Q 11-8.1$, $49=N Q 22-15.18,50=N Q 22-18.7,51=N Q 22-61.1,52=N Q 22-17.18,53=N Q 19-2.4,54=N Q 18-36.44,55=N Q 16-38.18,56=N Q 10-11.1$, $57=N Q 10-2.12 .8,58=K 2,59=K 3,60=A 25.9 .7,61=A 31.90,62=M R L-R F 24,63=P C 6684 K-, 64=M O P C 41,65=M 173 B, 66=G L O O P I$, $67=B X W-D N A 16,68=L 6,69=40-140,70=C P 5 B 5-3,71=V_{k} A R S, 72=P C 3386,73=38 C 13,74=V M 113,75=V_{k} 167,76=V_{k} 24 A, 77=V_{k} 24 B$, $78=A M 28,79=A M 29,80=A 15,81=25-39,82=K 5.1,83=K 1 A 5,84=K 18.1,85=W 3129,86=L X I X 27,87=J V 3,88=H P 9,89=B X W-D N A 14$, $90=V_{k} 139,91=$ GLOOP $5,92=A M 13,93=V S 3,94=A 17,95=J V 10,96=P Y 102,97=S 107 A, 98=V_{k} S e r, 99=M R L-R F 28,100=C E A 66-E 3$ $101=V-T N P, 102=B 6.2,103=C E M 231.6 .7,104=A 23,105=A 34,106=R F 49,107=R F 49 B, 108=R F 34,109=A M 16$. 
OO1 NIVLTQSPASLAVSLGORATISC RASESVDS. . YGNSFMH WYOOKPGOPPKLLIY LASNLES GVPARFSGSGSRTDFTLTIDPVEADDAATYC OQNNEDP

002 DIVLTOSPASLAVSLGQRATISC RASESVDS. YGNSFMH WYQQKPGQPPKLLIY RASNLES GIPARFSGSGSRTDFTLTINPVEADDVATYYC QOSNEDP

003 DIVLTQSPASLAVSLGQRATISC RASKSVST. SGYSYMH WYOOKPGOPPKLLIY LASNLES GVPARFSGSGSGTDFTLNIHPVEEEDAATYYC QHSRELP

004 DIVLTQSPASLAVSLGQRATISC RASOSVST. .SSYSYMH WYQQKPGQPPKLLIK YASNLES GVPARFSGSGSGTDFTLNIHPVEEEDTATYYC QHSWEIP

O05 DIVLTOSPASLAVSLGQRATIFC RASQSVDY. NGISYMH WFOQKPGQPPKLLIY AASNLES GIPARFSGSGSGTDFTLNIHPVEEEDAATYYC QQSIEDP

006 DIVLTQSPGSLAVSLGQRATISC RASESVES. . SGNNFIH WHQQKPGQPPXLLIY RASNLAS GIPARFSGSGSMTDFTLTINPVEADDVATYYC QQSNEDP

007 KIVLTOFPASLAVSLRQRATISC RASESVDS. YGNSFMY WYQQKPGQPPKLLIY RASNLES GVPARFSGSGSRTDFTLTIDPVEADDGATYYC QQNNEDP

008 DIVLTQSPASLAVSLGQSVTISC RASESVEY. YGSSLMQ WYQQKPGQPPKLLIY GASNVES GVPARFSGSGSGTDFSLNIHPVEEDDIAVYFC QQSRKVP

009 DIVLTQFPASLAVSLGQRATISY RASKSVST . .SGYSYMH WNQQKPGQPPRLLIY LVSNLES GVPARFSGSGSGTDFTLNIHPVEEEDAATYYC QHIREXK

010 DILLTOSPAILSVSPGERVSFSC RASQ...... SIGTSIH WYQQRTNGSPRLLIK YASESIS GIPSRFSGSGSGTDFTLSINSVESEDIADYYC QQSNSWP

011 DILLTQSPAILSVSPGERVSFSC RASQ . . . . SIGTSIH WYQQRTNGSPRLLIK NASESIS GIPSRFSGSGSGTDFTPSINSVESEDIAEYYC QQSYRWP

012 DILLTOSPAILSVSPGERVSFSC RASQ ..... SIGTSLH WYQQRTNGSPRLLIK YASESIS GIPSRFSGSGSGTDFTLSINSVESEDVADYYC QQTNSWP

013 DIVLTQSPATLSVTPGDSVSLSC RASQ ...... SIINNLH LYRUKSHESPRLLIK YASOSIS GIPSRFSGSGSGTDFTLSINSVETEDFGMYFC QQSNSWP

014 DIVLTQSPATLSVTPGDSVSLSC RASQ . . . . SISNNLH WYQQKSHESPRLLIN YASQSMS GIPSRFSGSGSGTDFTLSINSVETEDFGMYFC OQSNNWP

015 DIVLTQSPATLSVTPGDSVSLSC RASO..... SISNNLH WYOOKSHESPRLLIK YASOSIS GIPSRFSGSGSGTDFXLIINNVETEDFGMYFC QQSNSWP

016 DIVLTQSPATLSVTPRDSVSLSC RASO...... SISNNLH WYOOKSHESPRLLIK YASOSIS GIPSRFSGSGSGTDFTLSINSVETEDFGMYFC QQSNSWP

017 QIVLTQSPAIMSASPGEKVTMTC SARSS. . . . VSSSYLY WYQQKPGSSPKLWIY STSNLAS GVPARFSGSGSGTSYSLTISSMEAEDAATFYC QQYSGYP

018 ENVLTQSPAIMAASPGEKVTMTC SASSS. . . . VSSSNLH WYQQKSGTSTKFWIY RTSNLAS EVPAPFSGSGSGTSYSLTISSVEAEDAATYYC QQWSGYP

019 ENVLTQSPAIMAASLGQKVTMTC SASSS. . . . VSSSYLH WYQQKSGASPKPLIH RTSNLAS GVPARFSGSGSGTSYSLTISSVEAEDDATYYC QQWSGYP

020 ENVLTQSPAIMAASLGEKVTMTC SASSS. . . VSSSYLH WYQQKSGTSPKLWIY GTSNLAS GVPARFSGSGAGISYSLTISSMEAENDATYYC QOWSGYP

021 QIVLTQSPAIMSASPGEKVTMTC SASSS . . . . VSSKYLN WYQQRSGASPKLWIY GTSNLAS GVPARFSGSGSGTSYSLTISSVEAEDAATYYC QQYHSDP

022 QIVLTOSPAIMSASPGERVTMTC SASSS. . . VSSSYLY WYQQKPGSSPKLWIY STSNLAS GVPARFSGSGSGTSYSLTISSMEAED.AATYC QQYSGYP

023 EIVLTQSPTTMAXSPGEKITITC SANSS.... ISSNYLH WYQQKPGFSPKLLIY RTSNLAS GVQARFSGSGXVTSYSLTIGTMEAXDXATYYC QQGSSIP

024 ENVLTQSPAIMSASPGXKVTMTC RASSS . . . VSSSYLH WYQQKSGASPKLWIY STSNLAS XVPARFSGSGSGTSYSLTISSVEAEDAATYYC QQYSGYP

025 EIVLTOSPTTMAASPGEKITITC SASSS. . . . ISSNYLN WFQQKPGFSPKLLIY RTSNLAS GVPDRFSXSGSXTSYSLTIGTMEAEDVATYYC OQGSSIP

026 EIVLTQSPALMAASPGEKVTITC SVSSS. . . . ISSSNLH WYQQKSETSPKSWIY GTSNLAS GVPVRFSGSGSGTSYSLTISSMEAEDAATYYC QQWSSYP

027 QIVLTQSPAFMSASLGERVTMTC TARSS .... VSSSYFH WYQQKPGSSPKLWIY STSNLAS GVPTRFSGSGSGTSYSLTISSMEAEDAATYYC HQYHRSP

O28 EILLTQSPAIIAASPGEKVTITC SASS . . . . . SUSYMN WYQQKPGSSPKIWIY GISNLAS GVPARFSGSGSGTSFSFTINSMEAEDVATYYC QQRSSYP

029 QIVLTQSPAIMSASPGEKVTMTC SASS . . . . . SISYMH WYQQKPGTSPKRWIY DTSKLAS GVPARFSGSGSGTSYSLTISSMEAEDAATYYC HQRSSYP

030 ENVLTQSPAIMSASLGEKVTMSC RASS....... SVNYMY WYQQKSDASPKLWIY YTSNLAP GVPARFSGSGSGNSYSLTISSMEGEDAATYYC QQFTSSP

031 GIVLTQSPTTMTAFPGENVTITC SASS. . . . . SINYIH WYQQKSGNTPKQUIY KTSDLPS GVPTLFSGSGSGTSYSLTISSVEAEDAATYYC QQWSGYP

032 QIVLTQSPAIMSASPGEKVTMTC SASS . . . . . SVSYMH WYQQKSGTSPKRWIY DTSKLAS GVPARESGSGSGTSYSLTISSMEAEDAATYYC QQWSSNP

033 QIVLTQSPAIMSASPGEKVTISC SASS . . ..... SUSYMY WYQQKPGSSPKPWIY RTSNLAS GVPARFSGSGSGTSYSLTISSMEAEDAATYYC QQYHSYP

034 EIVLTQSPAITAASLGQKVTITC SASS . . . . . SUSYMH WYQQKSGTSPKPWIY EISKLAS GVPARFSGSGSGTSYSLTISSMEAEDAAIYYC QQWNYPP

035 QIVLTQSPAILSASPGEKVTMTC SASS . . . . . SVSYMU WFQQKPGSSPKLWIY SISNLAS GVPARFSGSGSGTSYSLTISSVKAEDAATYYC QOWSSSP

036 QILLTQSPAIMSASPGEKVTMTC SASS . . . . . SVSYMH WYQQKPGSSPKPWIY DTSNLAS GFPARFSGSGSGTSYSLIISSMEAEDAATYYC HORSSYP

037 QIVLTQSPALMSASPGEKVTMTC SASS...... SVSYMY WYQQKPRSSPKPWIY LTSNLAS GVPARFSGSGSGTSYSLTISSMEAEDAATYYC QQWSSNP

038 QIVLSQSPAILSASPGEKVTLTC RASS . . . . . SVSFMN WYQQKPGSSPKPWIY ATSNLAS EFPGRFSGEWSGTSYSLAISRVEAEDAATYYC QQWNSNP

039 QIVLSQSPAILSASPGEKVTMTC RASS. . . . . SVSYMH WYQQKLGSSPKPWIY ATSNLAS GVPARFSGSGSGTSYSLTISRVEAEDAATYYC QQWSSNP

040 QIVLTQSPAIMSASPGQKVTITC SASS. . . . . SVNYMH WYQQKLGSSPKLWIY DTSKLAP GVPARFSGSGSGTSYSLTISSMEAEDAASYFC HQWSSYP

041 QIVLSQSPAILSASPGEKVTMIC RASS . . . . . SVSYMH WYQQKPGSSPKPWIY APSNLAS GVPARFSGSGSGTSYSLTISRVEAEDAATYYC QQWSFNP

042 QILLTQSPAIMSASPGQKVTMTC SASS. . . . . SUSYMY WYQQKPGSSPRLLIY DTSNLAS GVPVRFSGSGSATSYSLTITRMQAEDAATYYC QQWSSYP

043 QILLTQSPAIMSASPGQKVTMTC SASS ...... SVSYMH WYQQKSGTSPKRWIY DTSKLAS GVPARFSGSGSATSYSLTITSMQAEDAATYYC QQWSSNP

044 QNVLNQSPXIMSXSPGEKVTMTC SASS ...... SVSYMQ WFOQXSGTSPKRWIY DTSKLXS XVPTRFSXSGSGTXYSLTISSMEAEDAATYYC QQWSSNP

045 QIVLTQSPXIMSXSPGEKVTMTC SASS...... SURYMN WFQQKSGTSPKRWIY DTSKLSS GVPARXSGSGSGTSXSLTISSMEXEDXATYYC QQWSSNP

046 QIVLTQSPAIMSASPGEKVTMTC SASS . . . . . SVSYMN WFQOKSGTSPKRWIY DTSKLSS GVPPRFSGSXXGTSYSLTISSMEAEDAATYYC QQWNSNP

047 QIVLTQSPAIMSASPGEKVTMTC SASS...... IVSYVO WFQQKSGTSPKRWIS DTSKLPS GVPARFSGSGSGTSYSLTISSMEAEDAATYYC QQWTSNP

048 QIVLIQSPXIMSASPGXKXTMTC SASS ...... SUSYMN WYQQKSGTSPKRWIY DTSKLAS GVPARFSGSGSGTSYSLTISSMEAEDAATYYC QQWNSNP

049 QIVLTQSPPIMSASPGEKVTMTC SASS ...... SVSYLQ WFQQKSGTSPKRWIY DTSKLDS XVPARFSXSGSGTSYSLTISSMEAEDAATYYC QQWTSNP

050 QIVLTQSPAIMSASPGEKV' MTC SASS ...... SVSYMN WFQQKSGTSPKRWVF ATSKLXS GVPARFSGSGXGTSYSLTISSMEAEDAATYYC QQWSSNP

051 QVVLTOSPXIMSASPGXKVTMTC SASS . . . . . SVSYMQ WFQQKSGTSPKRLIF YTSKLTS GVPARFSXSGXGTSYSLTISSMEAEDAATYYC QQWSSNP

052 QIVLSQSPAILSASPGERVTLTC RASS ....... SVSYIQ WFQQKPGSSPKPWIH ATSKXAS GVPARFSGSGSGTSYSLTISRVEAEDAATFYC QQWSSNP

053 QIVLTQSPXIMSASPGEKVTMTC SASS . . . . . SVSFMQ WYQQKSGTSPKRWIY HTSKLAS GVPARFSXSGXGTSYSLTITSMEAEDAATYYC QQXSXNP

054 QIVLSQSPAILSASPGEQVTMTC RASS.......SVSYMH WYQQKPGSSPKPWIY ATSNXAS GVXARFSGSGSGTSYSLTISRVEAEDAATYYC QQWSSNP 
B

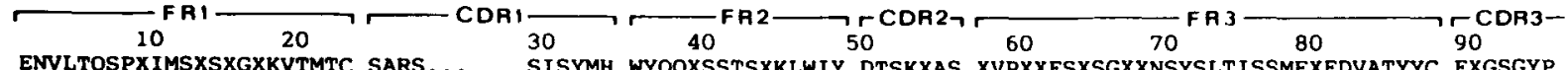
055 ENVLTOSPXIMSXSXGXKVTMTC SARS....... SISYMH WYQOXSSTSXKLWIY DTSKXAS XVPXXFSXSGXXNSYSLTISSMEXEDVATYYC FXGSGYP 056 OIVLSQSPAILSASPGEKVTMTC RASS. . . . . . SVSYIQ WFQQKPGSSPKPWIS VTSNLAS GVPARFSXSGSGTSYSLTISRVEAEDAATYYC QQWRSNP 057 OIVLSQSPAILSASPGEKVTMTC RASS....... SVSYIH WYOOKPGSSPKPWIY ATSNLAS GVPVRFSGSGSGTSYSLTINRVEAEDAATYYC QQWSSNP 058 DIOMTQSPASLSASVGETVTITC RASG. . . . . NIHNYLA WYQQKQGKSPQLLVY NAKTLAD GVPSRFSGSGSGTQYSLKINSLQPEDFGSYYC QHFWSTP 059 DIQMTQSPASLSVSVGETVTITC RASE. . . . NIYYSNLA WLFSRNRENPPSLVY AATNLAD GVPSRFSGSGSGTQYSLKINSQQPEDFGSYYC QHFWSAP 060 DIOMTOSPASLSASVGXTVTITC RASE. . . . . NIYSYLA WYQOKQGKSPQLLVY NAKTLAE GVPSRESGSGSGTQFSLKINSLQPEDFGSYYC QHHYVTP 061 DIQMTOSPASLSASVGXTVTITC RASE. . . . . NIYSYLA WYQQKQGKSPQLLVY NAKTLPE GVPSRFSGSGSGTQFSLKINSLQPEDFGSYYC QHHYGPP 062 DVQITOSPSYLAASPGETITINC RASK..... . SISKYLA WYQEKPGKTNKLLIY SGSTLQS GIPSRFSGSGSGTDFTLTISSLEPEDFAMYYC QQHNEYP 063 DVQMTQSPSSLSASLGERVSLTC QASQ . . . . SINNFLK WFQQTLGKTARLLIY GANKLED GVPSRFSGTGYGTDFTFTISSOEEEDVSTYFC LQHRYLP 064 DIQMTQSPSSLSASLGERUSLTC RASQ.... . DIGSSLN WLQQEPDGTIKRLIY ATSSLDS GVPKRFSGSRSGSDYSLTISSLESEDFVDYYC LQYASSP 065 DIOMTOSPSSLSASLGERVSLTC RASQ . . . . DIHGYLN LFQQKPGETIKHLIY ETSNLDS GVPKRFSGSRSGSDYSLIIGSLESEDFADYYC LQYASSP 066 DIOMTOSPSSLSASLGERVSLTC RASQ. . . . EISGYLS WLQQKPDGTIKRLIY AASTLDS GVPKRFSGSRSGSDYSLTISSLESEDFADYYC LQYLSYP 067 DIOMIQSPSSMFGSLGDRVSLSC RASQ. . . . . GIRGNLD WYQQKPGGTIKLLIY STSNLNS GVPSRFSGSGSGSDYSLTISSLESEDFADYYC LQRNAYP 068 DIKMTOSPSSMYASLGERVTITC KASQ. . . . DINSYLS WFQQKPGKSPKTLIY RANRLVD GVPSRFSGSGSGQDYSLTISSLEYEDMGIYYC LOYDEFP 069 DIKMTOSPSSMYASLGERVTISC KASQ . . . . . DINSYLT WFQQKPGKSPKTLLY RTKRLVD GVPSRFSGSGSGQEYSLTISSLEYEDMGIYFC LQYDEFL 070 DIKMTOSPSSMYASLGERVTITC KASQ. . . . DIKSYLS WYQQKPWXSPKTLIY YATSLAD GVPSRFSGSGSGXDYSLTISSLESDDTATYYC LQHGESP 071 DIQMTQTTSSLSASLGDRVTISC RASQ. . . . DISNYLN WYQQKPDGTVKLLIY YTSRLHS GVPSRFSGSGSGTDYSLTISNLEQEDIATYFC QQGNTLP 072 DIQMTQTTSSLSASPGDRVTISC RTSQ. . . . . DISNFLY WFQQKSDGTVKLLIY YTSRUHS GVPSRFSGSGSGTDYSFTINNLEUEDVATYSU QQGI 073 DIQMTQSPSSLSASLGGKVTITC KASQ ..... DINKYIA WDQHKPGKGPRLLIH YTSTIEP GIPSRFSGSGSGRDYSFSISNLEPEDIATYYC LQYDNLP 074 DIQMTQSPSSLSASLGGKVTITC KASQ..... DINKYLA WYQHKPGKGPRLLIH YTSTLQP GIPSRFSGSGSGRDYSFSISNLDAEEIATYYC LQYDSLY 075 DIVITQDELSNPVTSGESVSISC RSSKSLLYK.DGKTYLN WFLQRPGQSPQLLIY LMSTRAS GVSDRFSGSGSGTDFTLEISRVKAEDVGVYYC QQLVEYP 076 DIVMTQAAFSNPVTLGTSASISC RSSKSLLHS.SGNTYLY WFLQKPGQSPQLLIY YISNLAS GVPDRFSGSGSGTDFTLRISRVEAEDVGVYYC MQGLEYP 077 DIVMTQAAFSNPVTLGTSASISC RSSKSLLHS. NGITYLY WYLQKPGQSPQLLIY QMSNLAS GVPDRFSSSGSGTDFTLRISRVEAEDVGVYYC AQNLELP 078 DIVMTQAAPSVSUTPGESVFISC RSSKSLLHS. NGNTYLY WYLQRPGQSPQLLIY RMSNLAS GVPDRFSGSGSGTAFTLRISRVEAEDVGIYYC MQHLEYP 079 DIVMTQATPSVSUTPGESVFISC RSSKSLLYI.NGNTYLY WYLQRPGQSPQLLIY RMSYLAS GVPDRFSGSGSGTAFTLRISRVEAEDVGIYYC MQHLEYP 080 DIVMTQAAPSVPVTPGESVSVSC RSSKSLLHS. NGNTYLY WFLQRPGQSPQLLIY RMSNLAS GVPDRFSGSGSGTAFTLRISRVEAEDVGVYYC MOHLEYP 081 DIVMTQAAFSNPVTLGTSASISC RSSKNLLHS. NGITFLY WYLQRPGQSPQLLIY RVSNLAS GVPNRFSGSESGTDFTLRISRVEAEDVGVYYC AQLLEL 082 DVVMTOTPLSLPVSLGDQASISC RSSQSLVHS. NGNTYLH WYLQKPGQSPKLLIY KVSNRFS GVPDRFSGSGSGTDFTLKISRVEAEDLGVYFC SQSTHVP 083 DVLMTOTPLSLPVSLGDQASISC RSSQSIVHS. NGNTYLE WYLQKPGQSPKLLIY KVSNRFS GVPDRFSGSGSGTDFTLKISRVEAEDLGVYYC FQGSHVP 084 DAVMTQTPLSLPVSLGDQASISC RSSQSLENS. NGNTYLK WYLQKPGQSPQLLIY RVSNRFS GVLDRFSGSGSGTDFTLKISRVEAEDLGVYFC LQVTHAP 085 DVVVTQTPLSLPVSFGDQVSISC RSSQSLATS.HGITYLS WYLHKPGQSPQLLIY GISNRFS GVPDRFSGSGSGTDFTLKINTIKPEDLGMYYC LQGSHQP 086 DVVMTQTPLSLPVSLGDQASISC RSSQSIVHS.NGNTYLY WYLQKPGQSPKLLIY RVSNRFS GVPDRFSGSGSGTDFTLNISRVEAEDMGVYYC FQGTHVP 087 DAVMTQTPLSLPVSLGDQASISC RSSQSIENS. NGNTYLN WYLQKPGQSPRLLIY RVSNRFS GVLDRFSGSGSGTDFTLKISRVEAEDLGVYFC LQVTHVP 088 DIVMTOTPLSLPVSLGDQASISC RSSQSIVIS. NGFTYLE WYLQKPXXXXKLLIY GISNRFS GVPDRFSGSGSGTDFTLKISRVEAEDVGIYYC FQGIHVP 089 DVVMTQTPLTLSVTIGQPASISC KSSQSLLDS.DGKTYLN WLLQRPGQSPKRLIY LVSKLDS GVPDRFTGSGSGTDFTLKISRVEAEDLGVYYC WQGTHFP 090 DIVMTOSPSSLAMSVGOKVTMSC KSSQSLLNSSNQKNYLA WYQQKPGQSPKLLVY FASTRES GVPDRFIGSGSGTDFTLTISSVQAEDLADYFC QQHYSTP 091 GIVMSQSPSSLAVSVGEKVTMSC KSSQSLFYSSNOKNSLA WYQQRPGQSPKLLIY WASTRES GVPDRFTGSGSGTDFTLTISSVKAEDLAVYYC QQYYSYP 092 DIVMTQSPSSLTVTAGEKVTMSC KSSQSLLNSGNPKNYLT WYQQKPGQPPKLLIY WASTRES GVPDRFTGSGSGTDFTLTISSVQAEDLAVYYC QNDYSYP 093 DIVMTQSPSSLSVSAGEKVTMSC KSSQSLLNSGNQKNYLA WYQOKPGOPPKLLIY GASTRES GVPDRFTGSGSGTDFTLTISSVQAEDLALYYC QNDHTYP 094 NIMMTQSPSSLAVSAGEKVTMSC KSSQSVLYSSNQKNYLA WYQQKPGOSPKLLIY WASTRES GVPDRFTGSGSGTDFTLTISSVQAEDLAVYYC HQYLSS 095 DVVMSQSPSSLAVSAGEKVAVSC KSSQSLSTVEPERSYLA WYOQKPGQSPKLLIY WASTRES GVPDRFTGSGSGTDFTLTISSVRAEDLAVYYC KNLMDLP 096 XIVMTQSXXSLSVSAGXKVTMSC KSSQXLXNSXVKRTNLA WYXKKPGQPXKLLIS VDARPXH GVPDRFTGSGSGXDYTLTVSSVKAEDLALYYC QQHYXYP 097 DIVMTOSPTFLAVTASKKVTISC TXSESLYSSKHKVHYLA WYQKKPEQSPKLLIY GASNRYI GVPDRFTGSGSGTDFTLTISSVQVEDLTHYYC AQFYSYP 098 SIVMTQTPKFLLVSAGERVTITC KASO...... SUSNDVA WYQQKPGQSPKLLIY YASNRYT GVPDRFTGSGYGTDFTFTISTVQAEDLAVYFC QQDYSSP 099 SIVMTQTPKFLPVSAGDRVTMTC KASQ . . . . . SVGNNVA WYQOKPGQSPKLLIY YASNRYT GVPDRFTGSGSGTDFTFTISSVQVEDLAVYFC QQHYSSP 100 DIVMTQSHKFMSTSVGDRVSITC KASQ. . . . DVGAAIA WYQQKPGQSPKLLIY WASTRHT GVPDRFTGSGSGTDFTLTISNVQSDDLADYFC QQYSGYP 101 DIVMTOSOKFMSTSVGDRVSITC KASQ . . . . . NVGTAVA WYOQKPGQSPKLLIY SASNRYT GVPDRFTGSGSGTDFTLTISNMQSEDLADYFC QQYSSYP 102 DIVMTQSQKFMSTSVGDRVSUTC KASQ . . . . NVVTNVA WYQQTPGQSPKALIY SASYRYS GVPDRFSGSGSGTDFTLTISNVQSGDLAEYFC QQYNSYP 103 DIVMTOSQKFMSTSVGDRVSITC KASQ. . . . . NVRTAV WYQOKPGQSPKALIY LASNRYT GVPDRFTGSGSGTDFTLTITNVQSEDLADYFC LQHWNYP 104 DIVMTQSHKFMSTSVGDRVSUTC KASQ. . . . . NVGTNVA WYQQKPGQSPKALIY SASYRYS GVPDRFTGSGSGTDFTLTISNVQSEDLAEYFC QQYNSCP 105 DIVMTOSOKFMSTSVGDRVSVTC KASQ. . . . NVGTNVA WYOQKPGQSPKALIY SASYRYS GVPDRFTGSGSGTDFTLTISNVQSEDLAVYFC QQYNSYP 106 DIVMTOSHKFMSTSVGDRVSITC KASQ...... DVSTTVA WYOQKPGQSPKLLIY SASYRYT GVPDRFTGSGSGTDFTFTISSVQAEDLAVYYC QQHYSTP 107 DIVMTQSHKFMSTSVGDRVSITC KASO...... DVSTAVA WYOOKPGQSPKLLIY SASYRYT GVPDRFTGSGSGTDFTFTISSVQAEDLAVYYC QQHYSTP 108 NIVMTQSPKSMSVSVGERVTLTC KASE....... NVVTYVS WYQQKPEQSPKLLIY GASNRYT GVPDRFTGSGSATDFTLTISSVQAEDLADYHC GOGYSYP 109 NIVMTQSPKSMSMSVGERVTLSC KASE. . . . . NVGTYVS WYQQKPEQSPKLLIY GASNRYT GVPDRFTGSGSATDFTLTISSVQSEDLADYFC GQSYSYP

Fig. 2. Amino acid sequences deduced from $109 \mathrm{~V}_{\mathrm{k}}$ nucleic acid sequences contained in the $\mathrm{V}_{\mathrm{k}}$ database. Dots have been introduced to maximize homology; X, undetermined amino acids. Remainder of legend as for Figure 1. 
Table 1. $V_{k}$ nucleic acid sequence database*

\begin{tabular}{|c|c|c|c|c|c|c|c|}
\hline $\operatorname{Code}^{+}$ & $V_{k}^{*}$ & Group $^{*}$ & Subgroup ${ }^{*}$ & Specll & Strain ${ }^{8}$ & Class & $\operatorname{Ref}^{*}$ \\
\hline $001-005$ & 21 & III & 21 & G & $\mathrm{BALB} / \mathrm{c}$ & N/A & (1) \\
\hline 006 & & & & $\mathrm{HA}$ & $\mathrm{BALB} / \mathrm{c}$ & IgG & (2) \\
\hline 007,008 & & & & RF & $\mathrm{MRL} / p r$ & IgG & (3) \\
\hline 009 & & & & nf & BALB/c & N/A & (4) \\
\hline 010 & 23 & $\mathrm{v}$ & 23 & G & $\mathrm{BALB} / \mathrm{c}$ & $\mathrm{N} / \mathrm{A}$ & (5) \\
\hline 011 & & & & nf & $\mathrm{N} / \mathrm{R}$ & N/A & (6) \\
\hline 012 & & & & RNA & $(\mathrm{NZB} \times \mathrm{W}) \mathrm{F}_{1}$ & $\mathrm{IgG}$ & (7) \\
\hline 013 & & & & nf & $\mathrm{MRL} / \mathrm{n}$ & N/A & (8) \\
\hline 014,015 & & & & Anti-ID & C57BL $/ 6$ & IgG & (9) \\
\hline 016 & & & & $\mathrm{CK}$ & $\mathrm{BALB} / \mathrm{c}$ & $\operatorname{IgG}$ & (10) \\
\hline 017-019 & $4 / 5$ & IV & 4,5 & G & BALB/c & N/A & (11) \\
\hline 020 & & & & G & $\mathrm{BALB} / \mathrm{c}$ & N/A & (12) \\
\hline 021 & & & & histone & $\mathrm{MRL} / l p r$ & IgG & (13) \\
\hline 022 & & & & DNA & $\mathrm{MRL} / p r$ & IgM & (14) \\
\hline 023,024 & & & & ox & $\mathrm{BALB} / \mathrm{c}$ & $\mathrm{IgG}$ & (15) \\
\hline 025 & & & & ox & $\mathrm{BALB} / \mathrm{c}$ & $\mathrm{IgG}$ & (16) \\
\hline 026 & & & & RF & BALB/c & IgM & (17) \\
\hline 027 & & & & ALP & $\mathrm{BALB} / \mathrm{c}$ & IgG & (18) \\
\hline $028-032$ & & VI & 4 & $\mathrm{G}$ & $\mathrm{BALB} / \mathrm{c}$ & N/A & (11) \\
\hline 033-038 & & & & $\mathrm{CaAg}$ & BALB $/ \mathrm{c}$ & IgG & (19) \\
\hline 039 & & & & unknown & BALB/c & IgM & (20) \\
\hline 040 & & & & $\mathrm{RF}$ & $\mathrm{MRL} / l p r$ & $\operatorname{lgM}$ & (3) \\
\hline 041 & & & & CD20 & $\mathrm{BALB} / \mathrm{c}$ & $\mathrm{IgG}$ & (21) \\
\hline 042,043 & $4 / 5$ & VI & 4 & ox & $\mathrm{BALB} / \mathrm{c}$ & $\operatorname{IgG}$ & (22) \\
\hline 044-048 & & & & ox & $\mathrm{BALB} / \mathrm{c}$ & IgG & (23) \\
\hline $049-054$ & & & & ox & BALB/c & $\operatorname{IgG}$ & (16) \\
\hline 055 & & & & OX & $\mathrm{BALB} / \mathrm{c}$ & IgM & (16) \\
\hline 056 & & & & ox & BALB/c & IgG & (15) \\
\hline 057 & & & & ox & BALB/c & IgM & (15) \\
\hline 058,059 & $12 / 13$ & $\mathrm{~V}$ & $12-13$ & G & $\mathrm{BALB} / \mathrm{c}$ & N/A & (24) \\
\hline 060,061 & & & & Anti-ID & C57BL/6 & $\operatorname{IgG}$ & (9) \\
\hline 062 & $\mathrm{RF}$ & $\mathrm{v}$ & ambiguous & $\mathbf{R F}$ & $\mathrm{MRL} / l p r$ & IgM & (13) \\
\hline 063 & 11 & $\mathrm{v}$ & 11 & nf & NZB & N/A & (25) \\
\hline 064 & $9 \mathrm{~A}$ & v & 9 & $\mathrm{G}$ & $\mathrm{BALB} / \mathrm{c}$ & N/A & (26) \\
\hline 065 & & & & G & $\mathrm{BALB} / \mathrm{c}$ & N/A & (27) \\
\hline 066 & & & & lysozyme & $\mathrm{BALB} / \mathrm{c}$ & IgG & (28) \\
\hline 067 & & & & DNA & $(\mathrm{NZB} \times W) \mathrm{F}_{1}$ & IgM & (14) \\
\hline 068 & 9B & $\mathrm{v}$ & 9 & G & BALB/c & N/A & (5) \\
\hline 069 & & & & digoxin & $\mathrm{A} / \mathrm{J}$ & IgG & (29) \\
\hline 070 & & & & BrRBC & $\mathrm{CBA} / \mathrm{J}$ & IgM & (30) \\
\hline 071 & 10 & v & 10 & G & $\mathbf{A} / \mathbf{J}$ & $\mathrm{N} / \mathrm{A}$ & (31) \\
\hline 072 & & & & $\mathrm{nf}$ & NZB & N/A & (25) \\
\hline 073 & $38 \mathrm{C}$ & $\mathrm{V}$ & ambiguous & unknown & $\mathrm{C} 3 \mathrm{H} / \mathrm{HeN}$ & IgM & (32) \\
\hline 074 & & & & $\mathrm{HA}$ & $\mathrm{BALB} / \mathrm{c}$ & $\mathrm{IgG}$ & (33) \\
\hline 075 & $24 / 25$ & II & 24 & G & $\mathrm{BALB} / \mathrm{c}$ & $\mathrm{N} / \mathrm{A}$ & (34) \\
\hline 076,077 & & & & G & BALB $/ \mathrm{c}$ & N/A & (35) \\
\hline 078,079 & & & & $\mathrm{RF}$ & $\mathrm{C} 3 \mathrm{H} / \mathrm{lpr}$ & $\operatorname{IgA}$ & (3) \\
\hline 080 & & & & $\mathrm{RF}$ & $\mathrm{BALB} / \mathrm{c}$ & IgM & (17) \\
\hline 081 & & & & GAC & $\mathrm{A} / \mathrm{J}$ & IgG & (36) \\
\hline $082-084$ & 1 & II & 1 & G & BALB/c & N/A & (37) \\
\hline 085 & & & & dextran & $\mathrm{BALB} / \mathrm{c}$ & IgA & (38) \\
\hline 086 & & & & GAT & BALB/c & IgG & (39) \\
\hline 087 & & & & $\mathrm{RF}$ & BALB/c & IgM & (17) \\
\hline 088 & & & & Anti-ID & BALB/c & IgG & (40) \\
\hline 089 & 2 & II & 2 & DNA & $\left(\mathrm{NZB} \times \mathrm{W}^{\prime} \mathrm{F}_{1}\right.$ & IgM & (14) \\
\hline 090 & 8 & I & 8 & DNP & BALB $/ \mathrm{c}$ & IgA & (41) \\
\hline 091 & & & & HEL & BALB/c & IgG & (28) \\
\hline 092 & & & & $\mathrm{RF}$ & $\mathrm{MRL} / l p r$ & IgA & (3) \\
\hline 093,094 & & & & RF & $\mathrm{BALB} / \mathrm{c}$ & IgM & (17) \\
\hline 095 & & & & $\mathrm{RF}$ & $129 / \mathrm{Sv}$ & IgM & (17) \\
\hline 096 & & & & HA & $\mathrm{BALB} / \mathrm{c}$ & IgG & (33) \\
\hline 097 & 22 & I & 22 & PC & $\mathrm{BALB} / \mathrm{c}$ & IgA & (42) \\
\hline 098 & $19 / 28$ & V & 28 & G & BALB/c & N/A & (43) \\
\hline 099 & & & & $\mathrm{RF}$ & MRL/lpr & IgM & (8) \\
\hline 100 & & & $14-15-19$ & CEA & $\mathrm{BALB} / \mathrm{c}$ & IgG & (44) \\
\hline 101 & & & & TNP & BALB/c & IgM & (45) \\
\hline 102 & & & & CASA & N/R & IgG & (46) \\
\hline 103 & & & & CEA & $\mathrm{N} / \mathrm{R}$ & IgG & (47) \\
\hline 104-108 & & & & $\mathrm{RF}$ & $\mathrm{BALB} / \mathrm{c}$ & IgM & (17) \\
\hline 109 & & & & $\mathrm{RF}$ & $\mathrm{MRL} / l p r$ & IgG & (3) \\
\hline
\end{tabular}

$V_{k} 4 / 5$ gene family. $V_{k} T r p$ subgroups $V_{k} 4$ (groups IV and VI) and $V_{k} 5$ (group IV) were encoded by highly similar (around 90\%) genes forming a gene family, termed $V_{k} 4 / 5$, that was separated from all other $V_{k}$ sequences by $>25 \%$ of their nucleotides. This was the largest $V_{k}$ gene family, composed of approximately 25-50 members, as deduced from RFLP (Kofler et al. 1989) and gene cloning (Even et al. 1985) studies. Fourteen germline genes (ten $V_{k} 4$ and four $V_{k} 5$ genes) have been isolated thus far (Even et al. 1985, Höchtl et al. 1982). $V_{k} 4 / 5$ genes were found in antibodies specific for galactan (Heller et al. 1987), oxazolone (Kaartinen and Maekelae 1987, Berek and Milstein 1987), dextran (Sikder et al. 1985, Akolkar et al. 1987), the lymphocyte surface marker CD20 (Liu 1987b), alprenolol (Nahmias et al. 1988), red blood cells (Pennell et al. 1988), and DNA, histone, and Ig self antigens (Shlomchik et al. 1987c, Kofler et al. 1987b, Kofler et al. 1988a, Shlomchik et al. 1987b).

$V_{k} 12 / 13$ gene family. The sequences encoding $V_{\mathrm{k}} 12-13$ proteins (group V) formed another well-defined family that corresponded to all $\mathrm{V}_{\mathrm{k}} 12-13$ subgroup proteins (Kabat et al. 1987, Potter et al. 1982). Two germline genes have been published (Nishioka and Leder 1980, Seidman et al. 1978), one of which (K2) may be involved in the nitrophenyl-specific anti-idiotypic response (Sablitzky and Rajewsky 1984). A more distant $V_{k} 12 / 13$ gene encoded anti-idiotypic light chains in the GAT

* Only sequences encoding the entire mature $V_{k}$ region and differing by $>4$ bp are contained in this database (see Methods).

${ }^{\dagger}$ Codes of $\boldsymbol{V}_{k}$ genes are given in legend to Figure 1.

${ }^{\ddagger} V_{k}, V_{k}$ gene family (this report); Group, $V_{k}$ protein groups (Kabat et al. 1987); Subgroup, $V_{k} T r p 35$ subgroups (Potter et al. 1982).

Abbreviations: Spec, specificity; Ref, references; G, germline sequence; N/A, not applicable: HA, influenza hemagglutinin; RF, rheumatoid factor; nf, nonfunctional; N/R, not reported, Anti-ID, idiotype-specific antibody; CK, creatine kinase; OX, 2-phenyloxazolone; ALP, alprenolol; $\mathrm{CaAg}$, carbohydrate antigen on human carcinoma cells; CD20, lymphocyte surface marker; BrRBC, bromelain-treated red blood cells; GAC, group A carbohydrate; GAT, Glu $\mathrm{Ala}^{30} \mathrm{Tyr}^{10}$ polypeptide; DNP, dinitrophenyl; HEL, hen egg lysozyme; CEA, carcino-embryonal antigen; TNP, trinitrophenyl; CASA, cancer-associated surface antigen.

$\$$ Strains and their $I g k$ haplotypes (Kofler et al. 1989): $I g k^{a}: \mathrm{MRL} / l p r, \mathrm{MRL} / \mathbf{n}$; $l g k^{b}: \mathrm{NZB} ; \lg ^{c}: \mathrm{BALB} / \mathrm{c}, \mathrm{C} 57 \mathrm{BL} / 6, \mathrm{~A} / \mathrm{J}, \mathrm{C} 3 \mathrm{H}, \mathrm{CBA} / \mathrm{J}, 129 / \mathrm{Sv}, \mathrm{NZW}$

\# References: 1, (Heinrich et al. 1984); 2, (Clarke et al. 1985); 3, (Shlomchìk et al. 1987c); 4, (Strohal et al. 1987); 5, (Pech et al. 1981); 6, (Altenburger et al. 1980); 7, (Eilat et al. 1988); 8, (Kofler et al. 1989); 9, (Sablitzky and Rajewsky 1984); 10, (Buckel et al. 1987); 11, (Even et al. 1985); 12, (Höchtl et al. 1982); 13, (Kofler et al. 1987b); 14, (Kofler et al. 1988); 15, (Berek et al. 1985); 16, (Berek et al. 1987); 17, (Shlomchik et al. 1987a); 18, (Nahmias et al. 1988); 19, (Liu et al. 1987); 20, (Parslow et al. 1984); 21, (Liu 1987); 22, (Kaartinen et al. 1983); 23, (Griffiths et al. 1984); 24, (Seidman et al. 1978); 25, (Kelley et ai. 1985); 26, (Seidman et al. 1979); 27, (Max et al. 1980); 28, (Darsley and Rees 1985); 29, (Near and Haber 1989); 30, (Reininger et al. 1987); 31, (Sanz and Capra 1987); 32, (Campbell 1987); 33, (Meek et al. 1989); 34, (Selsing and Storb 1981); 35, (Joho et al. 1984); 36, (Lutz and Davie 1988); 37, (Corbet et al. 1987); 38, (Borden and Kabat 1987); 39, (Schiff et al. 1983); 40, (Ollier et al. 1985); 41, (Riley et al. 1986); 42, (Kwan et al. 1981); 43, (Boyd et al. 1986); 44, (Cabilly et al 1984); 45, (Hawley et al. 1982); 46, (Sahagan 1986); 47, (Beidler et al. 1988). 
Table 2. Correlation between $V_{k}$ gene families and $V_{k}$ protein groups and subgroups*.

\begin{tabular}{llll}
\hline $\begin{array}{l}V_{k} \text { gene } \\
\text { family }\end{array}$ & $\begin{array}{l}\mathrm{V}_{\mathrm{k}} \text { Cys } \\
\text { subgroup }\end{array}$ & $\begin{array}{l}\mathrm{V}_{\mathbf{k}} \text { Trp } \\
\text { subgroup }\end{array}$ & $\begin{array}{l}\mathrm{V}_{\mathrm{k}} \text { protein } \\
\text { group }\end{array}$ \\
\hline 21 & 21 & 21 & III \\
23 & 23 & 23 & $\mathrm{~V}$ \\
$4 / 5$ & 4 & 4 & $\mathrm{IV}, \mathrm{VI}$ \\
$12 / 13$ & 5 & 5 & IV \\
$\mathrm{RF}$ & 12,13 & $12-13$ & $\mathrm{~V}$ \\
11 & ambiguous assignment & V \\
$9 \mathrm{~A}$ & 11 & 11 & $\mathrm{~V}$ \\
$9 \mathrm{~B}$ & 9 & 9 & $\mathrm{~V}$ \\
10 & 9 & 9 & $\mathrm{~V}$ \\
$38 \mathrm{C}$ & 10 & 10 & $\mathrm{~V}$ \\
$24 / 25$ & ambiguous assignment & V \\
1 & 24 & 24 & II \\
2 & 25 & 25 & II, I \\
8 & $1,3,26$ & 1 & II \\
22 & 2 & 2 & II \\
$19 / 28$ & 8 & 8 & I \\
& 22 & 22 & I \\
\hline
\end{tabular}

* Relatedness between $V_{k}$ gene families and $V_{k} T$ rp subgroups 20 and 27 , and $V_{k}$ Cys subgroups $6,7,16,17$, and 18 (for which only partial protein sequences are known), could not be determined.

$\left(\mathrm{Glu}^{60} \mathrm{Ala}^{30} \mathrm{Tyr}^{10}\right.$ ) system (Ollier et al. 1985). In RFLP analyses, two strongly and several weakly hybridizing restriction fragments were observed (Kofler et al. 1989). Whether the latter corresponded to additional, more distant, $V_{k} 12 / 13$ germline genes or are due to high similarity $(>80 \%)$ in portions of the probe with other $V_{k}$ genes (particularly those of $V_{k}$ gene families $9 A, 9 B, 10$, and 11) remains to be determined.

$V_{k} R F$ gene family. The MRL-RF24 $\mathrm{V}_{\mathrm{k}}$ protein (Kofler et al. 1987b), a member of the large protein group $V$, had 12 mismatches up to Trp35 from two $\mathrm{V}_{\mathrm{k}} 12-13$ proteins (K2 and MOPC129), but differed from the remaining $\mathrm{V}_{\mathrm{k}} 12-13$ proteins (and all other $\mathrm{V}_{\mathrm{k}}$ proteins) by $>12$ residues. Thus, this protein could not be unambiguously assigned to known $V_{k}$ subgroups. Its nucleic acid sequence differed from all $V_{k}$ sequences by $>25 \%$, thus forming a distinct $V_{k}$ gene family, termed $V_{k} R F$. Used as a probe, this gene identified a single restriction fragment that was absent in haplotype $I g k^{f}$ (Kofler et al. 1989). The corresponding (as yet uncloned) germline gene probably also encoded a BALB/c (Bruck et al. 1986) and a C57BL/6 (Sablitzky and Rajewsky 1984) idiotypespecific antibody, as well as an $(\mathrm{NZB} \times \mathrm{NZW}) \mathrm{F}_{1}$ DNAspecific autoantibody (Eilat et al. 1988).

$V_{k} 11,9 A, 9 B, 10$, and $38 C$ gene families. The $V_{k}$ gene families discussed thus far were clearly separated from all other $V_{k}$ genes by $>25 \%$ overall sequence dissimilarity and in this respect resembled $V_{H}$ gene families. The following five gene families, distantly related to $V_{k} 12 / 13$ and $V_{k} R F$, were less well separated from one another.

$V_{k} 11$ gene family. For this gene family with four to six germline genes by RFLP analysis (Kofler et al. 1989), a single nucleic acid sequence corresponding to a nonfunctional rearrangement from an NZB myeloma (Kelley et al. 1985) was present in the data bank. This sequence fulfilled protein assignment criteria for $\mathrm{V}_{\mathrm{k}}$ protein subgroups 9,10 , and 11 ; however, it best matched $V_{k} 11$ proteins. Comparisons with the entire data bank (including some $V_{k} 9$ and $V_{k} 10$ sequences) revealed matches of only $76 \%$ or less at the nucleic acid level, making this sequence the prototype for the $V_{k} 11$ gene family. $V_{k} 11$ proteins were observed in the beta 2, 1 fructosan response (Kabat et al. 1987).

$V_{k} 9 A$ gene family. The $\mathrm{V}_{\mathrm{k}} 9$ protein subgroup, another member of the large protein group V (Potter et al. 1982), comprised sequences that, at the nucleic acid level, fell into two distinct gene families, termed $V_{k} 9 A$ and $V_{k} 9 B$. The $V_{k} 9 A$ gene family included two germline genes (Seidman et al. 1979, Max et al. 1980), one of which may be expressed in hen egg lysozyme antibodies (Darsley and Rees 1985). Another expressed $V_{k} 9 A$ gene from an $\mathrm{NZB} \times \mathrm{NZW} \mathrm{F}_{1}$ anti-DNA IgM (Kofler et al. 1988) was only $88 \%$ similar to the other germline gene and probably derived from an unknown $V_{k} 9 A$ germline gene. In addition, $V_{k} 9 A$ genes have been observed in GAT- idiotypespecific antibodies (Ollier et al. 1985).

$V_{k} 9 B$ gene family. The $\mathrm{T} 1$ sequence and its germline counterpart, V-L6 (Pech et al. 1981), both assigned to the $\mathrm{V}_{\mathrm{k}} \mathrm{9}$ protein subgroup (Potter et al. 1982), differed from $\mathrm{V}_{\mathrm{k}} 9 \mathrm{~A}$ (and all other $\mathrm{V}_{\mathrm{k}}$ ) nucleic acid sequences by $>20 \%$ and, hence, formed a separate family, termed $V_{k} 9 B$. Genes from this family encoded antibodies specific for digoxin (Panka and Margolies 1987, Near and Haber 1989) and Escherichia coli (Pennell et al. 1988), and bromelain-treated red blood cell autoantibodies from lupus and normal mice (Reininger et al. 1987).

$V_{k} 10$ gene family. This family corresponded to the $\mathrm{V}_{\mathrm{k}} 10$ subgroup (protein group V). RFLP data suggested two to three $V_{k} 10$ germline genes (Kofler et al. 1989), one of which has been cloned (Sanz and Capra 1987, Wysocki et al. 1987) and probably encoded arsonate (Manser et al. 1987a, Meek et al. 1987), oxazolone (Berek et al. 1985), oligosaccharide (Matsuda and Kabat 1989), bromelain-treated red blood cell (Pennell et al. 1988) and RF-like (Shlomchik et al. 1987c) antibody responses. A more distant $V_{k} 10$ sequence, with multiple in-frame stop codons, has been observed as a nonfunctional allele of an 
NZB myeloma (Kelley et al. 1985), and might correspond to one of the uncloned $V_{k} 10$ germline genes.

$V_{k} 38 C$ gene family (tentative). The very similar $(97 \%)$ sequences encoding the 38C13 lymphoma (Campbell 1987) and the VM113 anti-hemagglutinin hybridoma (Meek et al. 1989) light chains, respectively, were $>20 \%$ different from all other $V_{k}$ nucleic acid sequences in the database and, hence, could not be assigned to any $V_{k}$ gene family; the closest matches (77-78\%) were observed with a $V_{k} 10$ germline gene (Sanz and Capra 1987, Wysocki et al. 1987). At the amino acid level, members of four $V_{k} T r p$ subgroups $\left(V_{k} 9, V_{k} 10, V_{k} 11\right.$, and $\left.V_{k} 12 / 13\right)$ exhibited equally distant relatedness (nine and more residues difference in the $\mathrm{N}$-terminal 35 amino acids), making unambiguous assignment at the protein level impossible. Whether these sequences were the representatives of a new $V_{k}$ gene family or corresponded to highly mutated $\left(V_{k} 10\right)$ genes remains to be determined.

$V_{k} 24 / 25, V_{k} 1$, and $V_{k} 2$ gene families. The next three families were grouped together based on sequence similarity of up to $78 \%$ between $V_{k} 24 / 25$ members and $V_{k} l$ and $V_{k} 2$ genes, respectively, and because the overall similarity between $V_{k} 2$ and some $V_{k} 1$ genes exceeded $80 \%$. The latter observation, i. e., similarity of $>80 \%$ between some, but not all, members of two gene families, obviously constitutes a problem in this type of $V_{k}$ gene classification (see below).

$V_{k} 24 / 25$ gene family. Originally, only a single $V_{k} 24$ germline gene (involved in the phosphocholine response; Malipiero et al. 1987, Gearhart and Bogenhagen 1983) had been reported (Selsing and Storb 1981). Other investigators have cloned this, a related pseudogene, and two additional $V_{k} 24$ germline genes (Joho et al. 1984). The latter were only about $82-83 \%$ similar to the $V_{k} 24$ prototype and may have encoded Streptococcus group A carbohydrate antibody light chains previously assigned to the $V_{k} 25$ subgroup (Lutz and Davie 1988). Hence, these two $\mathrm{V}_{\mathrm{k}} \operatorname{Trp}$ subgroups (protein group II) were probably encoded by distant members of a single $V_{k}$ gene family. In addition to the four cloned $V_{k} 24 / 25$ germline genes, evidence was obtained for the presence of at least two more germline genes in this family: firstly, RFs from autoimmune and normal mice (Shlomchik et al. 1987a, $1987 \mathrm{c}$ ) expressed $V_{k} 24$ genes very similar to each other, but $>30$ bp different from the closest $V_{k} 24$ germline gene, suggesting an additional germline gene; secondly, since all cloned $V_{k} 24 / 25$ genes had 40 codons up to Trp35, the germline gene encoding Hy2.5.13 with $41 \mathrm{~N}$ terminal amino acids (Kabat et al. 1987) has yet to be isolated.

$V_{k} 1$ and $V_{k} 2$ gene families. Protein subgroups $V_{k} 1$ (already previously condensed with Cys 23 subgroups
$V_{k} 3$ and $V_{k} 26$; Potter et al. 1982) and $V_{k} 2$ were encoded by sequences that, using a stringent family definition, precluded classification into either a single, or two distinct, gene families; all $V_{k} 1$ nucleic acid sequences were $>80 \%$ similar, yet the three almost identical $V_{k} 2$ nucleic acid sequences reported (Akolkar et al. 1987, Kofler et al. 1988, Panka et al. 1988) shared up to $81.7 \%$ similarity with some, but only about $75 \%$ with other, $V_{k} I$ members. Moreover, sequence similarity in the $3^{\prime}$ portion of several $V_{k} 1$ and $V_{k} 2$ genes was around $90 \%$. These two "gene families" were, therefore, partially overlapping. However, for reasons of clarity, we have retained them as separate $V_{k}$ gene families.

Three $V_{k} I$ germline genes (Corbet et al. 1987) and approximately 40 expressed $V_{k} 1$ sequences have been reported. With the exception of an anti-dextran $V_{k}$ gene (W3129; Borden and Kabat 1987) with $>15 \%$ differences from any known $V_{k} l$ gene, all expressed sequences were highly homologous to one of the above germline genes, suggesting that the total $V_{k} l$ germline gene number may not exceed four. A more direct complexity estimate in our previous RFLP analysis was hampered by crosshybridization of the $V_{k} 1$ probe to non- $V_{k} I$ genes due to $>80 \%$ sequence similarity in the $3^{\prime}$ region of $V_{k} l$ and other $V_{k}$ genes (see below and Kofler et al. 1989). $V_{k} l$ genes were used in a variety of responses to foreign and self antigens (reviewed by Schiff et al. 1988, Kofler et al. 1987a). $V_{k} 2$ germline genes have not yet been reported; the three expressed sequences encoded antibodies to dextran (Akolkar et al. 1987), digoxin (Panka et al. 1988), and DNA (Kofler et al. 1988).

$V_{k} 8, V_{k} 22$, and $V_{k} 19 / 28$ gene families. The following three gene families were separated from each other by $>20 \%$, and from all other $V_{k}$ genes by $>25 \%$, overall sequence similarity; however, large portions (codons 35 to 94 ) of their genes had between $80 \%$ and $89 \%$ common nucleotides, leading to extensive cross-hybridizations (Kofler et al. 1989).

$V_{k} 8$ gene family. All sequences encoding $\mathrm{V}_{\mathrm{k}} \mathrm{Trp}$ subgroup $\mathrm{V}_{\mathrm{k}} 8$ (protein group I) were around $90 \%$ similar and shared up to $78 \%$ of their nucleotides with $V_{k} 19 / 28$ and $V_{k} 22$ genes. Similarity in codons 35-94 was even higher, reaching $87 \%$ with $V_{k} 28$ genes. The complexity of this gene family was difficult to assess by RFLP analyses due to possible cross-hybridization, however, at least half of the 13-20 fragments hybridizing to a $V_{k} 8$ probe probably belonged to this large family (Kofler et al. 1989). $V_{k} 8$ genes encoded antibodies to phosphocholine (Malipiero et al. 1987), dinitrophenyl (Riley et al. 1986), and hen egg lysozyme (Darsley and Rees 1985), as well as RF-like (Shlomchik et al. 1987a, 1987c) and DNA-specific (Eilat et al. 1988) autoantibodies. 
$V_{k} 22$ gene family. The only two, almost identical, $\mathrm{V}_{\mathrm{k}} 22$ (protein group I) sequences available for comparison, S107A (Kwan et al. 1981) and HPCA97 (Berek 1984), revealed between $80 \%$ and $89 \%$ similarity with a large portion (codons 35 to 94 ) of all $V_{k} 19 / 28$ genes. The remaining nucleotides were, however, only $<70 \%$ similar, resulting in an overall similarity of $72 \%-75 \%$, thus refuting assignment of $V_{k} 22$ and $V_{k} 19 / 28$ genes to a common gene family. Similarity with $V_{k} 8$ genes was in the range of $75 \%-77 \%$ and mismatches were distributed evenly over the entire gene. RFLP analyses suggested one to two $V_{k} 22$ germline genes; additional weak restriction fragments hybridizing to a $V_{k} 22$ probe on Southern blots probably corresponded to genes from the $V_{k} 19 / 28$ and $V_{k} 8$ families (Kofler et al. 1989). $V_{k} 22$ genes encoded phosphocholine antibodies (Malipiero et al. 1987).

$V_{k} 19 / 28$ gene family. Sequences encoding $V_{\mathrm{k}} \operatorname{Trp}$ subgroups 19 (comprising $\mathrm{V}_{\mathrm{k}} \mathrm{Cys} 14$ and 15 sequences) and 28 were $>80 \%$ similar among each other and differed from all other $V_{k}$ genes (except $V_{k} 8$ and $V_{k} 22$, see above) by $>25 \%$. Thus, they were combined to a single $V_{k}$ gene family, which was termed $V_{k} 19 / 28$. However, this $V_{k}$ gene family (like some other $V_{k}$ gene families, see below) behaved atypically in nucleic acid hybridization studies as compared to $V_{H}$ gene families: different DNA probes from this family, i. e., a $V_{k} 19$ and a $V_{k} 28$ probe, did not hybridize to an identical, but to an overlapping, set of restriction fragments (Kofler et al. 1989). This could be explained by cross-hybridization of the $V_{k} 28$, but not the $V_{k} 19$, probe with $V_{k} 8$ genes.

RFLP data suggested four to six $V_{k} 19 / 28$ germline genes (Kofler et al. 1989), one of which, a $V_{k} 28$ germline gene, also known as $V_{k} S e r$, from haplotypes $I g k-V S e r^{a}$, $I g k-V S e r^{b}, I g k-V S e r^{c}$, and $I g k-V S e r{ }^{d}$, has been cloned (Boyd et al. 1986, Ponath et al. 1989). $V_{k} 19 / 28$ genes encoded antibodies to trinitrophenyl (Hawley et al. 1982), carcinoembryonic antigen (Cabilly et al. 1984, Beidler et al. 1988), human breast/lung/colon cancer cells (Sahagan 1986), influenza hemagglutinin (Meek et al. 1989), and an RNA-specific (Eilat et al. 1988) and some RF-like autoantibodies (Kofler et al. 1989, Shlomchik et al. 1987a, 1987c).

Relatedness between $V_{k}$ gene families and implications for nucleic acid hybridization assays with $V_{k}$ probes

Figure 3 shows the relatedness between different $V_{k}$ gene families as reflected by overall nucleic acid sequence similarity. A significant difference from $V_{H}$ gene families was apparent, since the latter are generally more distantly

\begin{tabular}{|c|c|c|c|c|c|c|c|c|c|c|c|c|c|c|c|}
\hline & Vk21 & Vk23 & $\operatorname{Vk} 4 / 5$ & Vk12/13 & VkRF & Vk11 & $\mathrm{Vk} 9 \mathrm{~A}$ & Vk $9 B$ & Vk10 & Vk38c & $V k 24 / 25$ & $\mathrm{Vk} 1$ & Vk2 & $\mathrm{Vk} 8$ & $\mathrm{Vk} 22$ \\
\hline vk23 & $65-67$ & & & & & & & & & & & & & & \\
\hline Vk $4 / 5$ & $62-71$ & $61-64$ & & & & & & & & & & & & & \\
\hline Vk12/13 & $62-64$ & $60-62$ & $60-64$ & & & & & & & & & & & & \\
\hline VkRF & $63-66$ & $65-67$ & $59-63$ & \% $10 \%$ & & & & & & & & & & & \\
\hline Vk11 & 61 & 63 & $58-62$ & 60.71 & 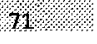 & & & & & & & & & & \\
\hline Vk $9 A$ & $61-67$ & $61-70$ & $63-67$ & $20 . \%$ & $69 \% 13$ & $69-12$ & & & & & & & & & \\
\hline Vk9B & $63-67$ & $61-65$ & $62-67$ & $10-7.3$ & $1,1-12.2$ & $24-76$ & $73-76$ & & & & & & & & \\
\hline Vk10 & $57-67$ & $63-66$ & $60-68$ & $65-71$ & $7,1,73$ & $11 \% 72:$ & $24-77$ & $71-75$ & & & & & & & \\
\hline $\mathrm{Vk} 38 \mathrm{c}$ & $60-65$ & $64-65$ & $59-64$ & 66.70 & $71 \%$. & 69 . & $69-72$ & 73 & $72-77$ & & & & & & \\
\hline$V k 24 / 25$ & $63-67$ & $59-60$ & $57-65$ & $57-61$ & $60-62$ & 57 & $58-63$ & $59-61$ & $58-60$ & $58-59$ & & & & & \\
\hline Vk1 & $62-68$ & $62-67$ & $58-62$ & $59-61$ & $59-62$ & $57-62$ & $57-64$ & $58-65$ & $57-63$ & 58-61 & $20-78$ & & & & \\
\hline $\mathrm{Vk} 2$ & $63-66$ & 61 & $56-60$ & $56-58$ & 61 & 60 & $59-61$ & $60-63$ & $58-59$ & 57 & $74-76$ & $73-81$ & & & \\
\hline Vk8 & $64-70$ & $61-65$ & $62-66$ & $60-63$ & $65-66$ & $61-63$ & $63-65$ & 65 & $60-61$ & $61-62$ & $62-68$ & 63-69 & $64-67$ & & \\
\hline Vk22 & $64-65$ & $61-62$ & $60-66$ & $58-60$ & 61 & 58 & $60-61$ & $60-62$ & $57-59$ & 58 & $60-63$ & $62-64$ & 63 & $75-72$ & \\
\hline Vk19/28 & $65-67$ & $62-66$ & $63-70$ & $58-62$ & $62-66$ & $63-65$ & $62-67$ & $65-70$ & $60-66$ & $59-64$ & $58-65$ & $60-66$ & $60-65$ & $72-78$ & \\
\hline
\end{tabular}

Fig. 3. Sequence similarity between different $V_{k}$ gene families; comparison of known germline genes and derivatives of putative germline genes (i. e., sequences differing from known germline genes by $>10 \%$ and primarily of the IgM isotype). Indicated are the highest and lowest percentages of nucleic acid sequence similarity between members from two families; single percentage resulted from comparisons yielding identical percentages. Shading intensities highlight increased overall similarity between the respective families. 
related by sequence similarity. Obviously, if members from different families are only a few percent less similar than those from within a family, cross-hybridizations might occur, particularly if these differences are not evenly distributed over the entire sequence. As described above, large sequence portions with high degrees of similarity were indeed observed in genes from families 8,22 , and $19 / 28$, and thus explain the previously observed cross-hybridizations between those families. Closer scrutiny of the similarities between portions of $\mathrm{V}_{\mathrm{k}}$ sequences from different families revealed that the $3^{\prime}$ region (particularly codons 57-88, corresponding to frame work region 3 ) were generally more closely related than the remaining sequence, and this portion might precipitate unexpected cross-hybridizations, even between otherwise distant $V_{k}$ gene families. For example, $V_{k} 10$ and $V_{k} 9 A$ genes had a 135 bp $3^{\prime}$ sequence with $83 \%$ similarity, and $V_{k} R F$ and $V_{k} 9 B$ genes shared $84 \%$ of 103 nucleotides at the $3^{\prime}$ end. As a further complication, different genes from a given family may exhibit more or less cross-hybridizations with genes from other families.

Because of the differences in the organization of $V_{H}$ and $V_{k}$ genes, nucleic acid sequence hybridization assays with $\mathrm{V}_{\mathrm{k}}$ DNA probes require particular care in the selection of probes and in data interpretation. While in general any member of a $V_{H}$ gene family used as a probe will recognize its entire family, but will not cross-hybridize with other families, our previous RFLP analyses and the current study strongly suggest that $V_{k}$ probes may often behave differently. As a rule, probes devoid of the more "promiscuous" 3' sequences will be more specific; however, such probes may not always hybridize to all members of their gene families, and therefore require the use of two or more genes to probe the entire family.

\section{$V_{k}$ germline gene complexity}

Another question addressed in this study regards the total number of $V_{k}$ genes in the genome of inbred mice. We estimated the complexity of known $V_{k}$ gene families by using RFLP criteria (Kofler et al. 1989) and by taking into account expressed and germline genes identified for each family. Regarding expressed sequences, we assumed that $\mathrm{IgM}$ sequences with $>6$, and IgG sequences with $>30$ mismatches from known germline genes may have derived from as yet unknown germline genes. Allelic differences were also considered, however this was a minor concern as the majority of sequences in the database $(91 / 109)$ derived from the same haplotype $\left(I g k^{\circ}\right)$.

This approach led to a total of about 70-140 genes (Table 3). Obviously, such estimates need to be taken with caution due to the peculiarities of $V_{k}$ gene probes discussed above, and to inherent limitations of the RFLP technique (discussed by Kofler et al. 1989). Furthermore,
Table 3. $V_{k}$ germline gene complexity*

\begin{tabular}{lll}
\hline$V_{k}$ gene family & \multicolumn{2}{l}{ Germline genes } \\
\cline { 2 - 3 } & Cloned & Estimated \\
\hline$V_{k} 2 l$ & 5 & $6-13$ \\
$V_{k} 23$ & 1 & $2-4$ \\
$V_{k} 4 / 5$ & 14 & $25-50$ \\
$V_{k} I 2 / 13$ & 2 & $2-8$ \\
$V_{k} R F$ & - & $0-1^{+}$ \\
$V_{k} l I$ & - & $4-6$ \\
$V_{k} 9 A$ & 2 & $4-9$ \\
$V_{k} 9 B$ & 1 & 2 \\
$V_{k} I 0$ & 1 & $2-3$ \\
$V_{k} 38 C$ & - & $?$ \\
$V_{k} 24 / 25$ & 4 & 6 \\
$V_{k} l$ & 3 & $4-6$ \\
$V_{k} 2$ & - & $1-6$ \\
$V_{k} 8$ & - & $5-16$ \\
$V_{k} 22$ & - & $1-2$ \\
$V_{k} l 9 / 28$ & - & $4-6$ \\
\hline Total & 35 & $66-136$ \\
\hline
\end{tabular}

* References to cloned $V_{k}$ germline genes are given throughout the text

* The one-member $V_{k} R F$ family is deleted in haplotype $I g k^{f}$ mice (Kofler et al. 1989).

possible additional, as yet uncloned, $V_{k}$ genes and gene families in the mouse genome have not been included. However, although evidence for some additional $V_{k}$ genes exists, their number might be limited. For two $\mathrm{V}_{k} \operatorname{Trp}$ subgroups, $\mathrm{V}_{\mathrm{k}} 27$ (group I) and $\mathrm{V}_{\mathrm{k}} 20$ (group VII), nucleic acid sequences have not been identified, but the corresponding $V_{k}$ gene families may be small since only a single sequence for each subgroup has been reported to date. D'Hoostelaere published another novel $V_{k}$ gene family ( $p C 9-26)$ with approximately six members as suggested by RFLP analyses (D'Hoostelaere et al. 1988), but whether or not this family related to either of the two subgroups above, or to $\mathrm{V}_{\mathrm{k}} 38 \mathrm{C}$, is unknown. Nevertheless, the large number of responses to foreign and self antigens investigated at the nucleic acid sequence level, and repeated isolation of identical sequences, suggest that the majority of the mouse $V_{k}$ germline repertoire might now be known.

Acknowledgments. We thank Dr. G. Wick for critically reviewing, and Ms. M. Kat Occhipinti for editing, this manuscript. The work reported herein was supported by a grant from the Austrian Research Council (Project S-41/06). R. Strohal is supported by a fellowship from the Emil Boral Stiftung and G. Kroemer receives an Erwin Schrödinger Stipend (J0307M) from the Austrian Research Council.

\section{References}

Akolkar, P. N., Sikder, S. K., Bhattacharya, S. B., Liao, J., Gruezo, F., Morrison, S. L., and Kabat, E. A.: Different $V_{L}$ and $V_{H}$ germline genes are used to produce similar combining sites with specificity for alpha $(1-->6)$ dextrans. $J$ Immunol 138 : 4472-4479, 1987 
Alt, F. W., Blackwell, K., DePinho, R. A., Reth, M.G., and Yancopoulos, G. D.: Regulation of genome rearrangement events during lymphocyte differentiation. Immunol Rev 89: 5-30, 1986

Altenburger, W., Steinmetz, M., and Zachau, H.G.: Functional and non-functional joining in immunoglobulin light chain genes of a mouse myeloma. Nature 287: 603-607, 1980

Beidler, C.B., Ludwig, J.R., Cardenas, J., Phelps, J., Papworth, C. G., Melcher, E., Sierzega, M., Myers, L. J., Unger, B. W., Fisher, M., David, G. S., and Johnson, M. J.: Cloning and high level expression of a chimeric antibody with specificity for human carcinoembryonic antigen. J Immunol 141: 4053-4060, 1988

Berek, C.: The D segment defines the T15 idiotope: the immunoresponse of A/J mice to Pneumococcus pneumoniae. Eur $J$ Immunol 14: 1043-1048, 1984

Berek, C. and Milstein, C.: Mutation drift and repertoire shift in the maturation of the immune response. Immunol Rev 96: 23-41, 1987

Berek, C., Griffiths, G. M., and Milstein, C.: Molecular events during maturation of the immune response to oxazolone. Nature 316: $412-418,1985$

Berek, C., Jarvis, J. M., and Milstein, C.: Activation of memory and virgin B cell clones in hyperimmune animals. Eur J Immunol 17: 1121,1987

Borden, P. and Kabat, E. A.: Nucleotide sequence of the cDNAs encoding the variable region heavy and light chains of a myeloma protein specific for the terminal nonreducing end of alpha (1-6) dextran. Proc Natl Acad Sci USA 84: 2440-2443, 1987

Boyd, T. M., Goldrick, M.M., and Gottlieb, P. D.: Structural differences in a single gene encoding the $V_{k}$ Ser group of light chains explain the existence of two mouse light-chain genetic markers. Proc Natl Acad Sci USA 83: 9134-9138, 1986

Brodeur, P. H. and Riblet, R.: The immunoglobulin heavy chain variable region (Igh-V) locus in the mouse. I. One hundred Igh-V genes comprise seven families of homologous genes. Eur J Immunol 14: 922-930, 1984

Bruck, C., Co, M. S., Slaoui, M., Gaulton, G. N., Smith, T., Fields, B. N., Mullins, J. I., and Greene, M. I.: Nucleic acid sequence of an internal image-bearing monoclonal anti-idiotype and its comparison to the sequence of the external antigen. Proc Natl Acad Sci USA 83: 6578-6582, 1986

Buckel, P., Huebner-Parajsz, C., Mattes, R., Lenz, H., Haug, H., and Beaucamp, K.: Cloning and nucleotide sequence of heavy- and light-chain cDNAs from creatine-kinase-specific monoclonal antibody. Gene 51: 13-19, 1987

Cabilly, S., Riggs, A. D., Pande, H., Shively, J.E., Holmes, W. E., Rey, M., Perry, L. J., Wetzel, R., and Heyneker, H. L.: Generation of antibody activity from immunoglobulin polypeptide chains produced in Escherichia coli. Proc Natl Acad Sci USA 81: 3273-3277, 1984

Campbell, M. J.: Idiotype vaccination against murine B cell lymphoma. Humoral and cellular responses elicited by tumor-derived immunoglobulin $\mathrm{M}$ and its molecular subunits. $J$ Immunol 139: 2825-2833, 1987

Clarke, S. H., Huppi, K., Ruezinsky, D., Staudt, L., Gerhard, W., and Weigert, M.: Inter- and intraclonal diversity in the antibody response to influenza hemagglutinin. J Exp Med 161: 687-704, 1985

Corbet, S., Milili, M., Fougereau, M., and Schiff, C.: Two $\mathrm{V}_{\mathrm{k}}$ germline genes related to the GAT idiotypic network (Abl and $\mathrm{Ab} 3 / \mathrm{Ab} 1^{\prime}$ ) account for the major subfamilies of the mouse $\mathrm{V}_{\mathbf{k}}-1$ variability subgroup. J Immunol 138: 932-939, 1987

Cory, S., Tyler, B. M., and Adams, J. M.: Sets of immunoglobulin $V_{k}$ genes homologous to ten cloned $V_{k}$ sequences: implications for the number of germline $\mathrm{V}_{\mathrm{k}}$ genes. J Mol Appl Genet 1: 103-116, 1981

Darsley, M.J. and Rees, A.R.: Nucleotide sequence of five antilysozyme monoclonal antibodies. EMBO J 4: 393-398, 1985

Devaux, C., Moinier, D., Mazza, G., Guo, X., Marchetto, S.,
Fougereau, M., and Rierres, M.: Preferential expression of $V_{k} 21 E$ on IdX Ia.7 positive monoclonal anti-I-E antibodies. $J$ Immunol 134: 4024-4030, 1985

D'Hoostelaere, L. A., Huppi, K., Mock, B., Mallett, C., and Potter, M.: The Igk $\mathrm{L}$ chain allelic groups among the Igk haplotypes and Igk crossover populations suggest a gene order. I Immunol 141: 652-661, 1988

Dildrop, R.: A new classification of mouse $\mathrm{V}_{\mathrm{H}}$ sequences. Immunol Today 5: 85-86, 1984

Eilat, D., Webster, D. M., and Rees, A. R.: V region sequences of antiDNA and anti-RNA autoantibodies from NZB/NZW F1 mice. $J$ Immunol 141: 1745-1753, 1988

Even, J., Griffiths, G. M., Berek, C., and Milstein, C.: Light chain germ-line genes and the immune response to 2-phenyloxazolone. EMBO J 4: 3439-3445, 1985

Gearhart, P. J. and Bogenhagen, D. F.: Clusters of point mutations are found exclusively around rearranged antibody variable genes. Proc Natl Acad Sci USA 80: 3439-3443, 1983

Griffiths, G. M., Berek, C., Kaartinen, M., and Milstein, C.: Somatic mutation and the maturation of immune response to 2-phenyloxazolone. Nature 312: 271-275, 1984

Hawley, R. G., Shulman, M.J., Murialdo, H., Gibson, D. M., and Hozumi, N.: Mutant immunoglobulin genes have repetitive DNA elements inserted into their intervening sequences. Proc Natl Acad Sci USA 79: 7425-7429, 1982

Heinrich, G., Traunecker, A., and Tonegawa, S.: Somatic mutation creates diversity in the major group of mouse immunoglobulin kappa light chains. J Exp Med 159: 417-435, 1984

Heller, M., Owens, J. D., Mushinski, J. F., and Rudikoff, S.: Amino acids at the site of $\mathrm{V}_{\mathrm{k}}-\mathrm{J}_{\mathrm{k}}$ recombination not encoded by germline sequences. J Exp Med 166: 637-646, 1987

Höchtl, J., Müller, C. R., and Zachau, H. G.: Recombined flanks of the variable and joining segments of immunoglobulin genes. Proc Natl Acad Sci USA 79: 1383-1387, 1982

Joho, R., Gershenfeld, H., and Weissman, I. L.: Evolution of a multigene family of $\mathrm{V}_{\mathrm{k}}$ germ line genes. EMBO J 3: 185-191, 1984

Kaartinen, M. and Maekelae, O.: Functional analogues of the $\mathrm{V}_{k} \mathrm{Ox} 1$ gene in different strains of mice: evolutionary conservation but diversity based on V-J joining. J Immunol 138: 1613-1617, 1987

Kaartinen, M., Griffiths, G. M., Markham, A. F., and Milstein, C.: mRNA sequences define an unusually restricted IgG response to 2-phenyloxazolone and its early diversification. Nature 304: 320-324, 1983

Kabat, E. A., Wu, T. T., Reid-Miller, M., Perry, H. M., and Gottesman, K.S.: Sequences of Proteins of Immunological Interest, 4 th edn, US Department of Health and Human Services, Public Health Service, National Institutes of Health, Bethesda, 1987

Kearney, J. F., Radbruch, A., Liesegang, B., and Rajewsky, K.: A mouse myeloma cell line that has lost immunoglobulin expression but permits the construction of antibody-searching hybrid cell lines. J Immunol 123: 1548-1550, 1979

Kelley, D. E., Wiedemann, L. M., Pittet, A. C., Strauss, S., Nelson, K. J., Davis, J., Van Ness, B., and Perry, R. P.: Nonproductive kappa immunoglobulin genes: recombinational abnormalities and other lesions affecting transcription, RNA processing, turnover, and translation. Mol Cell Biol 5: 1660-1675, 1985

Kofler, R.: A new murine Ig $\mathrm{V}_{\mathrm{H}}$ gene family. $J$ Immunol 140 . 4031-4034, 1988

Kofler, R., Dixon, F. J., and Theofilopoulos, A. N.: The genetic origin of autoantibodies. Immunol Today 8: 374-380, $1987 \mathrm{a}$

Kofler, R., Noonan, D. J., Strohal, R., Balderas, R. S., Møller, N.P. H., Dixon, F.J., and Theofilopoulos, A. N.: Molecular analysis of the murine lupus-associated anti-self response: involvement of a large number of heavy and light chain variable region genes. Eur J Immunol 17: 91-95, 1987b 
Kofler, R., Strohal, R., Balderas, R. S., Johnson, M. E., Noonan, D. J., Duchosal, M. A., Dixon, F.J., and Theofilopoulos, A. N.: Immunoglobulin $\mathbf{k}$ light chain variable region gene complex organization and immunoglobulin genes encoding anti-DNA autoantibodies in lupus mice. $J$ Clin Invest 82: 852-860, 1988

Kofler, R., Duchosal, M. A., and Dixon, F. J.: Complexity, polymorphism and connectivity of mouse $V_{k}$ gene families. Immunogenetics 29: $65-74,1989$

Kwan, S.-P., Rudikoff, S., Seidman, J. G., Leder, P., and Scharff, M. D.: Nucleic acid and protein sequences of phosphocholinebinding light chains. $J$ Exp Med 153: 1366-1370, 1981

Liu, A. Y.: Production of a mouse-human chimeric monoclonal antibody to CD20 with potent Fc-dependent biologic activity. $J$ Immunol 139: 3521, 1987

Liu, A. Y., Robinson, R. R., Hellström, K. E., Murray, E. D., Jr., Chang, C. P., and Hellström, I.: Chimeric mouse-human IgG1 antibody that can mediate lysis of cancer cells. Proc Natl Acad Sci USA 84: 3439-3443, 1987

Livant, D., Blatt, C., and Hood, L.: One heavy chain variable region gene segment subfamily in the BALB/c mouse contains 500-1000 or more members. Cell 47: 461-470, 1986

Lutz, C. T. and Davie, J. M.: Genetics and primary structure of $V_{k}$ gene segments encoding antibody to Streptococcal group A carbohydrate. Comparison of $V_{k}$ gene structure with idiotope expression. I Immunol 140: 641-645, 1988

Malipiero, U. V., Levy, N. S., and Gearhart, P. J.: Somatic mutation in anti-phosphorylcholine antibodies. Immunol Rev 96: 59-74, 1987

Manser, T., Parhami-Seren, B., Margolies, M. N., and Gefter, M. L.: Somatically mutated forms of a major anti-p-azophenylarsonate antibody variable region with drastically reduced affinity for $\mathrm{p}$-azophenylarsonate. By-products of an antigen-drive immune response? J Exp Med 166: 1456-1463, 1987a

Manser, T., Wysocki, L.J., Margolies, M.N., and Gefter, M. L.: Evolution of antibody variable region structure during the immune response. Immunol Rev 96: 141-162, 1987b

Matsuda, T. and Kabat, E. A.: Variable region cDNA sequences and antigen binding specificity of mouse monoclonal antibodies to isomaltosyl oligosaccharides coupled to proteins. T-dependent analogous of $\alpha(1-->6)$ dextran. J Immunol 142: 863-870, 1989

Max, E.E., Seidman, J. G., Miller, H., and Leder, P.: Variation in the crossover point of kappa immunoglobulin gene $\mathrm{V}-\mathrm{J}$ recombination: evidence from a cryptic gene. Cell 21: 793-799, 1980

Meek, K., Sanz, Z., Rathbun, G., Nisonoff, A., and Capra, J. D.: Identity of the $V_{k} 10$-Ars-A gene segments of the A/J and BALB/c strains. Proc Natl Acad Sci USA 84: 6244-6248, 1987

Meek, K., Johansson, B., Schulman, J., Bona, C., and Capra, J. D.: Nucleotide changes in sequential variants of influenza virus hemagglutinin genes and molecular structures of corresponding monoclonal antibodies specific for each variant. Proc Natl Acad Sci USA 86: 4664 4668, 1989

Nahmias, C., Strosberg, A.D., and Emorine, L. J.: The immune response toward beta-adrenergic ligands and their receptors. VIII. Extensive diversity of $\mathrm{V}_{\mathrm{H}}$ and $\mathrm{V}_{\mathrm{L}}$ genes encoding anti-alprenolol antibodies. J Immunol 140: 1304-1311, 1988

Near, R. I. and Haber, E.: Characterization of the heavy and light chain immunoglobulin variable region genes used in a set of anti-digoxin antibodies. Mol Immunol 26: 371-382, 1989

Nishioka, Y. and Leder, P.: Organization and complete sequence of identical embryonic and plasmacytoma kappa V-region genes. $J$ Biol Chem 255: 3691-3694, 1980

Ollier, P., Rocca-Serra, J., Somme, G., Theze, J., and Fougereau, M.: The idiotypic network and the internal image: possible regulation of a germ-line network by paucigene encoded $\mathrm{Ab} 2$ (anti-idiotypic) antibodies in the GAT system. EMBO J 4:3681-3688, 1985

Panka, D. J. and Margolies, M. N.: Complete variable region sequences of five homologous high affinity anti-digoxin antibodies. $J$ Immunol 139: 2385-2391, 1987

Panka, D. J., Mudgett-Hunter, M., Parks, D. R., Peterson, L. L., Herzenberg, L. A., Haber, E., and Margolies, M.N.: Variable region framework differences result in decreased or increased affinity of variant anti-digoxin antibodies. Proc Natl Acad Sci USA 85: 3080-3084, 1988

Parslow, T. G., Blair, D. L., Murphy, W. J., and Granner, D. K.: Structure of the $5^{\prime}$ ends of immunoglobulin genes: a novel conserved sequence. Proc Natl Acad Sci USA 81: 2650-2654, 1984

Pech, M., Höchtl, J., Schnell, H., and Zachau, H. G.: Differences between germ-line and rearranged immunoglobulin $V_{k}$ coding se quences suggest a localized mutation mechanism. Nature 291 . $668-670,1981$

Pennell, C. A., Arnold, L.W., Haughton, G., and Clarke, S. H. Restricted Ig variable region gene expression among $\mathrm{Ly}-\mathrm{1}^{+} \mathrm{B}$ cell lymphomas. J Immunol 141: 2788-2796, 1988

Perlmutter, R. M., Kearney, J.F., Chang, S.P., and Hood, L. E.: Developmentally controlled expression of immunoglobulin $\mathrm{V}_{\mathrm{H}}$ genes. Science 227: 1597-1601, 1985

Ponath, P. D., Hillis, D. M., and Gottlieb, P. D.: Structural and evolu tionary comparisons of four alleles of the mouse immunoglobulin kappa chain gene, Igk-VSer. Immunogenetics 29: 249-257, 1989

Potter, M.: Antigen-binding myeloma proteins of mice. Adv Immunol 25: $141-211,1977$

Potter, M., Newell, J. B., Rudikoff, S., and Haber, E.: Classification of mouse $V_{k}$ groups based on the partial amino acid sequence to the first invariant tryptophan: impact of $\mathbf{1 4}$ new sequences from IgG myeloma proteins. Mol Immunol 19: 1619-1630, 1982

Reininger, L., Ollier, P., Poncet, P., Kaushik, A., and Jaton, J. C.: Novel $\mathrm{V}$ genes encode virtually identical variable regions of six murine monoclonal anti-bromelain-treated red blood cell autoantibodies. J Immunol 138: 316-323, 1987

Reininger, L., Kaushik, A., Izui, S., and Jaton, J.-C.: A member of a new $V_{H}$ gene family encodes anti-bromelinized mouse red blood cell autoantibodies. Eur J Immunol 18: 1521-1526, 1988

Riley, S. C., Connors, S. J., Klinman, N.R., and Ogata, R.T.: Preferential expression of variable region heavy chain gene segments by predominant 2,4-dinitrophenyl-specific BALB/c neonatal antibody clonotypes. Proc Natl Acad Sci USA 83: 2589-2593, 1986

Sablitzky, F. and Rajewsky, K.: Molecular basis of an isogeneic antiidiotypic response. EMBO J 3: 3005-3012, 1984

Sahagan, B. G.: A genetically engineered murine/human chimeric antibody retains specificity for human tumor-associated antigen. $J \mathbf{~ m}$ munol 137: 1066, 1986

Sanz, I. and Capra, J. D.: $V_{k}$ and $J_{k}$ gene segments of A/J Ars-A antibodies: somatic recombination generates the essential arginine at the junction of the variable and joining regions. Proc Natl Acad Sci USA 84: 1085-1089, 1987

Schiff, C., Corbet, S., Milili, M., and Fougereau, M.: Interstrain conservation of the murine GAT-specific antibody $V_{k}$ repertoire as analyzed at the germline gene level. EMBO J 2: 1771-1776, 1983

Schiff, C., Corbet, S., and Fougereau, M.: The Ig germline gene repertoire: economy or wastage? Immunol Today 9: 10-14, 1988

Seidman, J. G., Leder, A., Edgell, M. H., Polsky, F., Tilghman, S. M., Tíemeier, D. C., and Leder, P.: Multiple related immunoglobulin variable-region genes identified by cloning and sequence analysis. Proc Natl Acad Sci USA 75: 3881-3885, 1978

Seidman, J. G., Max, E. E., and Leder, P.: A kappa-immunoglobulin gene is formed by site-specific recombination without further somatic mutation. Nature 280: 370-375, 1979

Selsing, E. and Storb, U.: Somatic mutation of immunoglobulin lightchain variable-region genes. Cell 25: 47-58, 1981

Shlomchik, M. Nemazee, D., Van Snick, J., and Weigert, M.: Variable region sequences of murine $\operatorname{IgM}$ anti-IgG monoclonal autoan- 
tibodies (rheumatoid factors). II. Comparison of hybridomas derived by lipopolysaccharide stimulation and secondary protein immunization. $J$ Exp Med 165: 970-987, 1987a

Shlomchik, M. J., Aucoin, A. H., Pisetsky, D. S., and Weigert, M. G.: Structure and function of anti-DNA autoantibodies derived from a single autoimmune mouse. Proc Natl Acad Sci USA 84: 9150-9154, $1987 \mathrm{~b}$

Shlomchik, M.J., Marshak-Rothstein, A., Wolfowicz, C. B., Rothstein, T. L., and Weigert, M. G.: The role of clonal selection and somatic mutation in autoimmunity. Nature 328: 805-811, 1987c

Sikder, S. K., Akolkar, P. N., Kaladas, P. M., Morrison, S. L., and Kabat, E. A.: Sequences of variable regions of hybridoma antibodies to alpha $(1->6)$ dextran in BALB/c and C57BL/6 mice. J Immunol 135: 4215-4221, 1985

Strohal, R., Kroemer, G., Wick, G., and Kofler, R.: Complete variable region sequence of a non-functionally rearranged kappa light chain transcribed in the non-secretor P3-X63-Ag8.653 myeloma cell line. Nucleic Acids Res 15: 2771, 1987
Tonegawa, S.: Somatic generation of antibody diversity. Nature 302: 575-581, 1983

Winter, E., Radbruch, A., and Krawinkel, U.: Members of novel $V_{H}$ gene families are found in VDJ regions of polyclonally activated B-lymphocytes. EMBO J 4: 2861-2867, 1985

Wysocki, L. J., Gridley, T., Huang, S., Grandea, A. G., and Gefter, $M$. L.: Single germline $V_{H}$ and $V_{k}$ genes encode predominating antibody variable regions elicited in strain A mice by immunization with p-azophenylarsonate. J Exp Med 166: 1-11, 1987

Yancopoulos, G. D., Desiderio, S. V., Paskind, M., Kearney, J. F., Baltimore, D., and Alt, F. W.: Preferential utilization of the most $\mathrm{J}_{\mathrm{H}}$-proximal $\mathrm{V}_{\mathrm{H}}$ gene segments in pre-B-cell lines. Nature 311 : $727-733,1984$

Received July 31, 1989; revised version received September 26, 1989. 